\title{
Where is the Value Added? Trade Liberalization and Production Networks ${ }^{\text {th }}$
}

\author{
Rahel Aichele \\ Ifo Institute - Leibniz Institute for Economic Research at the University of Munich, \\ Poschingerstr. 5, 81679 Munich, Germany; and CESifo. \\ Inga Heiland \\ University of Oslo, Department of Economics, Moltke Moes vei 31, 0851 Oslo, Norway; \\ CESifo; and Ifo Institute.
}

\begin{abstract}
To what extent has trade liberalization contributed to global production fragmentation and the formation of production networks? We derive structural equations for value added trade flows, the domestic value added content of exports (DVA) and the value added to exports (VAX) ratio, as well as modelbased measures for production networks from a multi-sector gravity model with inter-sectoral linkages. We calibrate the model and perform a counterfactual analysis of China's WTO accession in 2001. We find that the associated trade cost changes spurred global production fragmentation, explaining about $6-12 \%$ of the decrease in the world DVA ratio as observed between 2000 and 2007. For China, the counterfactual experiment robustly replicates the increase in its DVA ratio, driven by the export-processing zones. Furthermore, our results imply that China's WTO accession was a driving force behind the strengthening of production networks with its neighbors.
\end{abstract}

\footnotetext{
We thank Lorenzo Caliendo for valueable comments and for providing us with his program code. We also thank Wolfgang Keller, as well as seminar participants at Stanford University, UC Irvine, University of Munich, the GEP China/ifo/CEPII conference and the Annual meeting of the ETSG 2013, CEA 2015 and CIE 2015 for valuable comments and suggestions. Funding: This work was supported by the Deutsche Forschungsgemeinschaft (DFG) [grant number KO 1393/2-1 | YA 329/1-1/ AOBJ: 599001]; and the Leibniz Association [grant number SAW-2016-ifo-4].

Email addresses: aichele@ifo.de (Rahel Aichele), inga.heiland@econ.uio.no (Inga Heiland)
} 
Keywords:

Production fragmentation, global value chains, production networks, trade in value added, tariff liberalization, China's WTO accession

F13, F14, F17

\section{Introduction}

The global value chain is increasingly fragmented. Single stages of a good's production are performed in different countries, yielding consumption goods composed of value added from all over the world. As a consequence, traditional export statistics become less informative about the global pattern of production and income (Johnson and Noguera, 2012). As a case in point, Xing and Detert (2011) document that only about $4 \%$ of the value of an iPhone assembled in China and exported to the United States is Chinese value added. Also, vertically sliced production processes imply that goods cross borders multiple times at different production stages, driving a wedge between the value of exports observed at customs and the income generated in its production at home and abroad. Johnson and Noguera (2017) document that between 1970 and 2009 the ratio of world value added exports to world exports, an inverse measure of the degree of back-and-forth-trade along the value chain, fell from 87 to $79 \%$.

Production fragmentation multiplies the potential gains from specialization. However, it also makes it harder to understand the consequences of policy changes for production, trade, and welfare. Cost and demand changes spill over across production stages to sectors and countries further up or down the value chain. Moreover, with upstream value added in vertically sliced production processes crossing borders multiple times, the importance of fundamental determinants of trade relationships such as relative productivity differences and natural or political barriers to trade are magnified (Yi, 2003). In fact, Johnson and Noguera (2017) and Baldwin and LopezGonzalez (2015) document that the current engagement in trade along the production chain is very unevenly distributed across the globe. It is highly concentrated, taking place primarily within networks among geographically close nations, especially in North America, East Asia, and Europe.

In this paper, we analyze to what extent trade liberalization has contributed to global production fragmentation and the formation of production networks. To that end, we derive structural expressions for indicators 
of production sharing developed in the literature, such as the value added to export ratio (VAX ratio) proposed by Johnson and Noguera (2012) and the domestic value added content of exports ratio (DVA ratio) of Koopman et al. (2014), from a multi-sector, multi-country, general equilibrium trade model. ${ }^{1}$ In a similar spirit, we propose new model-based measures of production networks at the bilateral sectoral level. The model, which is a variant of Caliendo and Parro (2015), can straightforwardly be calibrated based on international input-output (IO) tables, and then be used to analyze the effects of changes in exogenous variables, such as trade costs, on the degree of production fragmentation, the structure of the global value chain and the intensity of production networks.

In our application, we consider China's accession to the World Trade Organization (WTO) in 2001. We simulate the impact of the associated tariff cuts on the structure of production networks involving China, the value added composition of China's exports, as well as on the global degree of production fragmentation. Our approach is related to recent work by Johnson and Noguera (2017), who analyze the effect of global trade agreements on world-wide production fragmentation in a structural model. Our paper seeks to contribute by providing model-based expressions for value added trade flows and production networks, and by providing a quantification of the local and global effects of one of the major instances of trade liberalization: China's entry into the WTO.

Global trade patterns in the 2000s were strongly affected by the exceptional growth of China, the world's major destination for processing and assembly of foreign components. Between 2000 and 2007, China's exports quadrupled, increasing its share in world exports from 4 to $8 \%$. In the early 2000s, however, China also experienced a remarkable trend reversal in the share of domestic value added content of trade, resisting the global downward trend. Koopman et al. (2012) were the first to document this sudden increase in the DVA ratio, after taking into account the differential IO structure of firms in China's export-processing zones. Using firm-level data on Chinese exporters, Kee and Tang (2016) provide compelling evidence that the increase in domestic value added content was causally related to China's

\footnotetext{
${ }^{1}$ Koopman et al. (2014) provide a general input-output-based value added accounting framework, connecting these two measures and earlier variants developed by Hummels et al. (2001) and Daudin et al. (2011).
} 
WTO entry and its differential effect on the cost of intermediate inputs for firms in the processing zones and the rest of China. They show that declining tariffs improved the competitiveness of China's upstream producers outside the processing zones, making them more attractive as suppliers for the processing segment. Aggregating firm-level DVA ratios across firms and sectors, they find that the increased competitiveness of domestically sourced value added for the processing firms dominated the effect of substitution of foreign for domestic value added in the non-processing segment, yielding a higher DVA ratio post-WTO-entry at the country level. Brandt and Morrow (2017) show that the increase in China's aggregate DVA ratio was also spurred by a disproportional increase in ordinary compared to processing exports.

Our analysis seeks to contribute to this literature by analyzing the effects of China's WTO entry by means of a counterfactual experiment in a general equilibrium model, where countries' production chains are integrated through sectoral IO linkages. In contrast to a firm-level study, this approach allows us to capture general equilibrium feedback effects on China through adjustments in the global pattern of goods and factor prices. Moreover, it permits an analysis of the effects on third countries and the global degree of production fragmentation. To capture the significant differences between the sourcing structures of China's processing and non-processing firms, we calibrate the model using the OECD's Inter-Country Input-Output (ICIO) Database. This database provides differentiated (internationalized) IO tables for four segments of the Chinese economy, based, respectively, on sectoral averages over firms selling only domestically, export-processing firms, non-processing exporters, and services firms.

To preview our results, we find that the counterfactual predictions of our model align well with the pattern of changes observed in the data between 2000 and 2007. They replicate the decline in the world DVA ratio as well as the opposite trend experienced by China, including the differential pattern of changes in DVA and VAX ratios across its economic segments which were induced by the erosion of the processing exporters' preferential tariff treatment. Consistent with the findings of Kee and Tang (2016) and Brandt and Morrow (2017), we find that the aggregate increase in China's DVA ratio was driven both by a higher domestic content share of processing exports and a relative shift towards ordinary exports, which contain significantly more domestic value added to begin with. In terms of magnitudes, we find that the tariff cuts associated with China's WTO accession can explain 93\% of the change in its DVA ratio observed in the data. At the world level, the 
predicted change in the DVA ratio amounts to $6 \%$ of the observed decline. These are sizeable effects if one takes into account that the only difference between the baseline and the counterfactual is the tariff structure of a single country. The counterfactual experiment does not consider growth in world GDP or growth in China due to anything other than the trade cost changes.

As a robustness check, we simulate a counterfactual scenario including estimated sectoral reductions in non-tariff barriers to trade (NTBs) on top of tariff cuts. These estimates, obtained from a structural gravity equation, capture among other reductions in unobserved trade barriers the effects of China's WTO entry on import quotas, product standards, trade policy uncertainty (TPU), intellectual property rights, and WTO-related investment liberalization. The predicted counterfactual changes are quantitatively larger compared to the tariff-cuts-only scenario, but reveal the same pattern of differential changes in DVA ratios across China's economic segments.

With respect to welfare, we find that the WTO-entry-induced tariff changes led to a $1.4 \%$ increase in real income for China, despite a substantial decline in tariff income. We find welfare effects above .5\% for its neighboring countries, as well as for the two countries experiencing the largest tariff cuts, Brazil and Argentina. We find very small, but positive effects also for the United States. Twelve countries, primarily middle-income countries outside Asia, experience a decline in their real income. These findings align well with existing literature that has evaluated the gains from trading with China in general equilibrium models (see, e.g., di Giovanni et al., 2014; Ghosh and Rao, 2010) and complement micro-level evidence that has drawn a more pessimistic picture of the consequences of trading with China, particularly for the United States (see, e.g., Autor et al., 2013). Given their short-term perspective on local employment, those results are not necessarily contradictory to ours. Our results reflect long-run effects and include general equilibrium adjustments, allowing for sectoral labor mobility to facilitate the value added increases on the national level, and for lower prices to increase real income.

Our analysis of the impact of trade liberalization involves an implicit comparison with alternative explanations for the increase in trade along the value chain over time that have been put forward by the literature on production fragmentation. Improvements in communication technology may have facilitated the unbundling of production processes into finer steps and eased the flow of knowledge across borders (Keller and Yeaple, 2013). Moreover, improvements in institutional quality and property rights protection might have mitigated contractual frictions inhibiting arms-length transactions (Antrás 
and Chor, 2013). Finally, increased demand for technologically more complex goods, in conjunction with economic growth and non-homotheticity of preferences, provide a demand-driven explanation. To compare the impact of China's WTO entry on global production fragmentation to other developments, we conduct various additional counterfactual experiments. Those suggest that the effect of China's WTO entry on the world DVA ratio accounts for 8 to $16 \%$ of the combined effect of global formation of trade agreements, WTO entries, and observed tariff changes between 2000 and 2007 and equals 7 to $14 \%$ of the effect of the decline in labor cost shares observed during that period.

The paper proceeds as follows. In Section 2, we derive structural expressions for value added trade and different measures of production fragmentation within the gravity model with IO linkages developed by Caliendo and Parro (2015), as well as a model-based definition of demand and supply networks. In Section 3, we describe our data sources and the model calibration, Section 4 describes how production fragmentation and networks involving China developed in the 2000s. Section 5 begins with a description of the policy changes in our counterfactual analysis and then presents the simulation results and robustness checks. In Section 6, we discuss results of additional counterfactual experiments to put our main findings into perspective. Section 7 discusses our approach and findings and concludes.

\section{A Model for Trade in Value Added}

Our analysis is based on Caliendo and Parro (2015)'s multi-sector gravity model with IO-linkages - with one twist: we allow trade costs to vary between intermediate and final goods imports. This implies differential trade shares across the two use categories. Besides aligning well with the data we use for model calibration, this extension enables us to capture the differential cost effects for China's processing segment. A detailed description of the model and its comparative statics are relegated to Online Appendix B. We add to this framework a model-based characterization of value added trade and production networks.

\subsection{Value Added Trade}

To derive value added trade flows between countries $i$ and $n$ via other countries $h$ in line with the concepts established by Johnson and Noguera (2012) and Koopman et al. (2014), we need information on bilateral final 
goods exports, a world IO table, and value added coefficients in all countries and sectors. From the extended Caliendo and Parro (2015) model, we obtain the shares of final and intermediate goods expenditure, $\pi_{h n}^{j_{f}}$ and $\pi_{h n}^{j_{m}}$, that country $n$ spends on varieties from country $h$ 's sector $j$ according to

$$
\pi_{h n}^{j_{\nu}}=\frac{\lambda_{h}^{j}\left(c_{h}^{j} \kappa_{h n}^{j_{\nu}}\right)^{-\theta^{j}}}{\sum_{h=1}^{N} \lambda_{h}^{j}\left(c_{h}^{j} \kappa_{h n}^{j_{\nu}}\right)^{-\theta^{j}}} \quad \text { for } \quad \nu \in(m, f),
$$

where $\lambda_{h}^{j}$ is the country-and-sector-specific location parameter of the exponential distribution of variety producers' productivity levels and $\theta^{j}$ governs the dispersion of productivity across variety producers in sector $j . c_{h}^{j}$ are the minimum costs of an input bundle of sector $j$ in country $h, \kappa_{h n}^{j_{f}}$ denotes trade frictions consisting of iceberg trade costs and ad-valorem tariffs. Country $n$ 's final goods expenditure on varieties from country $h$ (net of tariffs $\tau_{h n}^{j_{f}}$ ) is

$$
C_{h n}^{j}=\frac{\pi_{h n}^{j_{f}}}{1+\tau_{h n}^{j_{f}}} X_{n}^{j_{f}}
$$

where $X_{n}^{j_{f}}=\alpha_{n}^{j} I_{n}$ with $\alpha_{n}^{j}$ denoting the constant sectoral expenditure share and $I_{n}=w_{n} L_{n}+R_{n}-S_{n}$ denoting income comprised of the return to labor $w_{n} L_{n}$, tariff rebates $R_{n}$, and the (exogenous) trade surplus $S_{n}$ of country $n$.

From the variety producers' cost function we obtain the share of value added $V_{h}^{j}\left[\omega^{j}\right]$ in the production value of a typical variety $\omega^{j}$ in country $h$ using Shepard's lemma:

$$
V_{h}^{j}\left[\omega^{j}\right]=z_{h}^{j}\left[\omega^{j}\right]^{1 / \theta^{j}} \frac{\partial c_{h}^{j}}{\partial w_{h}} \frac{w_{h}}{z_{h}^{j}\left[\omega^{j}\right]^{1 / \theta^{j}} c_{h}^{j}}=\beta_{h}^{j},
$$

where $w_{h}$ denotes the wage rate, $z_{h}^{j}\left[\omega^{j}\right]$ denotes the inverse efficiency of variety producer $\omega^{j}$, and $\beta_{h}^{j}$ is the elasticity of output with respect to labor. Note that this share is independent of the producer's efficiency level. Similarly, we can derive IO coefficients, that is, the cost share of intermediates from sector $k$ in country $i$ in the production of goods in country $h$ 's sector $j$ as

$$
\left(1+\tau_{i h}^{k_{m}}\right) a_{i h}^{k, j}=\frac{\partial c_{h}^{j}}{\partial p_{i h}^{k_{m}}} \frac{p_{i h}^{k_{m}}}{c_{h}^{j}}=\pi_{i h}^{k_{m}}\left(1-\beta_{h}^{j}\right) \gamma_{h}^{k, j},
$$


where $p_{i h}^{k_{m}}$ denotes the price of intermediate good $k_{m}$ sourced in country $i$ and shipped to country $h$, and $\left(1-\beta_{h}^{j}\right) \gamma_{h}^{k, j}$ is the cost share of intermediates from source sector $k$, with $\gamma_{h}^{k, j} \in[0,1]$. We define $a_{i h}^{k, j}$ as the cost share net of tariffs because IO coefficients are usually denoted in producer prices.

We collect all bilateral IO coefficients $a_{i h}^{k, j}$ in a $N J \times N J$ world IO table A. $N, J$ denote the number of countries and sectors, respectively. Input coefficients are arranged in $N \times N$ submatrices of dimension $J \times J$, each comprising all cross-sectoral relationships of a country pair, that is, we write

$$
\mathbf{A}=\left(\begin{array}{ccc}
\mathbf{A}_{11} & \ldots & \mathbf{A}_{1 N} \\
\vdots & \ddots & \vdots \\
\mathbf{A}_{N 1} & \ldots & \mathbf{A}_{N N}
\end{array}\right) \text {, where } \mathbf{A}_{i h}=\left(\begin{array}{ccc}
a_{i h}^{1,1} & \ldots & a_{i h}^{1, J} \\
\vdots & \ddots & \vdots \\
a_{i h}^{J, 1} & \ldots & a_{i h}^{J, J}
\end{array}\right)
$$

Within each submatrix the row index $k$ of $a_{i h}^{k, j}$ corresponds to the supply sector and the column index $j$ denotes the demand sector, while the indices $i$ and $h$ of the submatrix denote the source country and destination country, respectively. Elements $b_{i h}^{k, j}$ of the Leontief inverse of the IO matrix, $\mathbf{B}=$ $(\mathbf{I}-\mathbf{A})^{-1}$, inform about the value of output that is generated in sector $k$ in country $i$ per unit (value) of final goods production in sector $j$ in country $h$. B takes into account the world-wide fragmentation of the value chain and intermediates trade.

Let $\mathbf{C}_{n}$ be a column vector collecting sectoral final goods imports of country $n$ from all countries $h$

$$
\mathbf{C}_{n} \equiv\left(\begin{array}{c}
\mathbf{C}_{1 n} \\
\vdots \\
\mathbf{C}_{N n}
\end{array}\right) \text {, where } \mathbf{C}_{h n} \equiv\left(\begin{array}{c}
C_{h n}^{1} \\
\vdots \\
C_{h n}^{J}
\end{array}\right)
$$

Then, $\mathbf{B} \cdot \mathbf{C}_{\mathbf{n}}$ is a $N J \times 1$ vector that collects the amount of production in country $i$ and sector $k$ for final demand in country $n$. An element of this vector is $\sum_{h=1}^{N} \sum_{j=1}^{J} b_{i h}^{k, j} C_{h n}^{j}$, which takes into account that sector $k$ 's output can reach country $n$ embodied in final goods imports from all sectors $j$ from all countries $h^{2}$ Value added generated in country $i$ 's sector $k$ that is assembled into a final good in country $h$ 's sector $j$ and finally consumed in country $n$ is

\footnotetext{
${ }^{2}$ Note that a general explicit closed-form solution for $b_{i h}^{k, j}$ does not exist.
} 


$$
V A_{i h n}^{k, j}=\beta_{i}^{k} b_{i h}^{k, j} C_{h n}^{j}=\beta_{i}^{k} b_{i h}^{k, j} \frac{\pi_{h n}^{j_{f}}}{1+\tau_{h n}^{j_{f}}} \alpha_{n}^{j} I_{n}
$$

By summing over $h$ we obtain the total value added from sector $k$ in country $i$ that reaches country $n$ embodied in final goods from sector $j$. Summing over all final goods sectors yields the total value added from sector $k$ in country $i$ that is consumed in country $n$ :

$$
V A_{i n}^{k}=\beta_{i}^{k} \sum_{j=1}^{J} \alpha_{n}^{j} I_{n} \sum_{h=1}^{N} b_{i h}^{k, j} \frac{\pi_{h n}^{j_{f}}}{1+\tau_{h n}^{j_{f}}}
$$

This expression provides a structural expression for value added exports as defined in Johnson and Noguera (2012), which can be subjected to counterfactual analysis in general equilibrium. To assess how bilateral value added flows change in response to a change in tariffs we proceed as follows: Once the equilibrium trade share changes are determined (see Appendix B, Eq. B.8), we can compute the counterfactual Leontief inverse and then the counterfactual bilateral value added flows. Denote with $\hat{x} \equiv x^{\prime} / x$ the relative change in any variable $x$ from its initial level $x$ to the counterfactual level $x^{\prime}$. Then, the counterfactual IO coefficients are

$$
a_{i h}^{k, j^{\prime}}=\frac{\hat{\pi}_{i h}^{k_{m}}}{\left(1+\tau_{i h}^{k_{m}}\right)} a_{i h}^{k, j} .
$$

We collect them in the counterfactual IO table $\mathbf{A}^{\prime}$. The counterfactual Leontief inverse is then simply $\mathbf{B}^{\prime}=\left(\mathbf{I}-\mathbf{A}^{\prime}\right)^{-1}$. Final goods trade in the counterfactual experiment is

$$
C_{h n}^{j^{\prime}}=\frac{\hat{\pi}_{h n}^{j_{f}} \pi_{h n}^{j_{f}}}{1+\tau_{h n}^{j_{f}^{\prime}}} \alpha_{n}^{j} I_{n}^{\prime}
$$

The counterfactual value added flows corresponding to Eqs. (5) and (6) result as

$$
V A_{i h n}^{k, j^{\prime}}=\beta_{i}^{k} I_{n}^{\prime} \alpha_{n}^{j} b_{i h}^{k, j^{\prime}} \frac{\hat{\pi}_{h n}^{j_{f}} \pi_{h n}^{j_{f}}}{1+\tau_{h n}^{j_{f}^{\prime}}} \quad \text { and } \quad V A_{i n}^{k^{\prime}}=\sum_{j=1}^{J} \sum_{h=1}^{N} V A_{i h n}^{k, j^{\prime}}
$$




\subsection{Aggregate Measures of Global Production Sharing: VAX and DVA Ratio}

Johnson and Noguera (2012) propose the ratio of a country's VAX ratio as a measure for its engagement in production sharing. In the context of our model, the VAX ratio is

$$
\frac{V A X_{i}}{E_{i}}=\frac{\sum_{n \neq i} \sum_{j} V A_{i n}^{j}}{\sum_{n \neq i} \sum_{j}\left(C_{i n}^{j}+\sum_{k} a_{i n}^{k, j} Y_{n}^{j}\right)}=\frac{\boldsymbol{\beta}_{i} \sum_{n}^{N} \sum_{m \neq i}^{N} \mathbf{B}_{i n} \mathbf{C}_{n m}}{\sum_{n \neq i} \sum_{j}\left(C_{i n}^{j}+\sum_{k} a_{i n}^{k, j} Y_{n}^{j}\right)} .
$$

where $E_{i}$ denotes exports, $Y_{n}^{j}$ is sectoral gross production value, and $\boldsymbol{\beta}_{i}$ is a $J \times J$ diagonal matrix with diagonal elements corresponding to country $i$ 's sectoral value added coefficients $\beta_{i}^{k}$. The VAX ratio computed at the country level is weakly smaller than one, reflecting the fact that trade along the value chain leads to double-counting of upstream value added, inflating gross export values over value added exports. Ceteris paribus, smaller VAX ratios indicate a greater degree of double counting and hence, more engagement in trade along the value chain.

Note that the value added flows in Eqs. (6) and (9) are tied to the value added content of final goods consumption in other countries. Koopman et al. (2014) show how any country's total export value can be decomposed into domestic and foreign value added and a share of export value caused by double counting of domestic and foreign value added. This research has motivated the use of the share of domestic value added (net of double counting) in exports (DVA ratio) as an alternative indicator for a country's engagement in global production sharing. At the country level, the DVA ratio differs from the VAX ratio only due to the fact that part of the domestic value added in exports (named RDV) ultimately returns home, embodied in imports from other countries. The DVA ratio at the country level is thus given by

$$
\frac{D V A_{i}}{E_{i}}=\frac{V A X_{i}}{E_{i}}+\frac{R D V_{i}}{E_{i}}
$$

Online Appendix C lays out in detail the decomposition equation developed by Koopman et al. (2014) expressed in terms of variables of our model. ${ }^{3}$

\footnotetext{
${ }^{3}$ A subtle difference to the original equation in Koopman et al. (2014) emerges from the fact that we take explicit account of the fact that IO coefficients in the data are valued
} 
When computed at the sectoral level, there is an additional difference between the two measures: The VAX ratio then measures the sector's own value added exports which may take place directly through its own or indirectly through another domestic sector's exports. Consequently, at the sectoral level the VAX ratio can exceed one. The DVA ratio, in contrast, measures value added from any domestic sector embodied in a given sector's gross export which is weakly smaller than one at any level of aggregation.

\subsection{Production Networks at the Sectoral Level}

To analyze cross-country dependencies through trade along the value chain, we propose a measure that can be used to identify production networks. The measure is based on the relationship between a source sector in one country, which we call the upstream sector, and a final goods producing downstream sector in another country. All the intermediate travel routes, including the second to last location from which the downstream sector imports the upstream sectors' value added, enter through the Leontief coefficients. To separate value added in intermediate and final goods production, we first define modified Leontief coefficients. Let $b_{i h}^{j, k}$ be any Leontief coefficient, that is, any element of $\mathbf{B}=(\mathbf{I}-\mathbf{A})^{-1}=\sum_{k=0}^{\infty} \mathbf{A}^{k}$ and denote with $\tilde{b}_{i h}^{k, j}$ the corresponding element of $\widetilde{\mathbf{B}}=\sum_{k=1}^{\infty} \mathbf{A}^{k}$. Then,

$$
\begin{array}{ccc}
b_{i h}^{k, j}=\tilde{b}_{i h}^{k, j} & \text { if } & i \neq h \vee k \neq j \\
b_{i h}^{k, j}=\tilde{b}_{i h}^{k, j}+1 & \text { if } & i=h \wedge k=j .
\end{array}
$$

$\tilde{b}_{i h}^{k, j}$ is the output created through intermediate goods production per unit of final goods output. This is identical to the Leontief coefficient if the demanding and supplying sectors are not identical (or not in the same country), because in those cases all output generated in the supplying sector through final goods production of the demanding sector must be through intermediates production. If the two sectors are identical, then the value of the final good itself is included in $b_{i i}^{k, k}$, given by the 1 that is added to $\tilde{b}_{i h}^{k, j}$.

The total value added from upstream sector $k$ that is processed into a final good by the downstream sector $j$ in country $h$ and from there exported to the world or consumed in $h$ can be obtained by summing up the expression

net of tariffs. This gives rise to an additional term collecting actual and double-counted tariff payments on imported intermediate inputs induced by final goods consumption. 
for value added flows in Eq. (5) over destination countries $n$

$$
\widetilde{V A}_{i h}^{k, j}=\beta_{i}^{k} \tilde{b}_{i h}^{k, j} C_{h W}^{j},
$$

where $C_{h W}^{j}$ is processing country $h$ 's total sales (domestic and exports) of final goods from sector $j$. Note that here we use the modified Leontief coefficients $\tilde{b}_{i h}^{k, j}$ that do not include value added generated in final goods production.

To evaluate the intensity of such a value-added-trade relationship, we can focus on either the upstream or the downstream sector, which are, respectively, tied to the source country of value added or to the final goods producing country. Furthermore, we can look at the value added trade relationship from either the demand side or the supply side by comparing any flow given by Eq. (11) to the total value from the upstream sector that is processed elsewhere, or to the total value added processed by the downstream sector. We call the former a "demand network", the latter a "supply network."

We first look at a so-defined supply network and focus on the downstream sector $j_{d}$. Sector $j_{d}$ uses value added from all upstream sectors in country $i$ to produce final goods for the world. We define such a value added trade relationship between $j_{d}$ in $h$ and all sectors $k$ in country $i$ as intense if the share of value added from country $i$ processed by $j_{d}$ relative to the total value added from all sources that $j_{d}$ processes is large. This measure is given by ${ }^{4}$

$$
s n_{i h}^{j_{d}}:=\frac{\widetilde{V A}_{i h}^{\cdot j_{d}}}{\widetilde{V A}_{. h}^{\cdot j_{d}}}=\sum_{k=1}^{J} \frac{\beta_{i}^{k} \tilde{b}_{i h}^{k, j_{d}}}{\sum_{i}^{N} \sum_{k}^{J} \beta_{i}^{k} \tilde{b}_{i h}^{k, j_{d}}} .
$$

Alternatively, we can look at production network intensity from the point of view of an upstream sector $k_{u}$ and describe its production relationship with final goods producers in another country $h$. We define this sort of value added trade relationship as intense if the share of $k_{u}{ }^{\prime}$ s value added processed in country $h$ relative to the total value added from $k_{u}$ processed elsewhere is large. This measure is given by

$$
d n_{i h}^{k_{u}}:=\frac{\widetilde{V A}_{i h}^{k_{u}}}{\widetilde{V A}_{i .}^{k_{u}} .}=\sum_{j=1}^{J} \frac{\tilde{b}_{i h}^{k_{u}, j} C_{h W}^{j}}{\sum_{h}^{N} \sum_{j}^{J} \tilde{b}_{i h}^{k_{u}, j} C_{h W}^{j}} .
$$

\footnotetext{
${ }^{4}$ Dots in place of indices indicate that we have summed over the respective dimension.
} 
Below, we describe the evolution of production networks with China in the 2000s and analyze the contribution of China's WTO entry to these changes. This IO-based view on interlinkages has advantages and disadvantages. By summarizing all indirect production relationships, Leontief-inverse based decompositions do not allow for a step-by-step analysis of all sequential production stages. Nor can it capture differences in the structure of the value chain, as discussed by Baldwin and Venables (2013). On the positive side, our Leontief-coefficient-based network indicator provides a measure of the depth of a production relationship that simultaneously takes into account all possible linkages between countries, thus rendering feasible a general equilibrium analysis of value added flows in a global model. Moreover, our supply and demand network indicators are easy to calibrate for multiple countries and sectors at various points in time based on international IO databases.

\section{Data and Model Calibration}

To simulate the effects of changes in trade costs, we need to calibrate the model parameters $\alpha, \beta, \gamma$, and $\theta$, and collect data on bilateral trade shares, tariff levels, countries' total output, final goods expenditure, and trade surpluses. The model is calibrated to 2000, the year prior to China's WTO accession.

\subsection{Data Sources}

Our main data source is the OECD's ICIO Database that provides harmonized international IO tables as well as production values, final and intermediate goods trade, and consumption. The database contains data for 63 countries and a rest-of-the-world aggregate (RoW) for the years 1996-2011, with a sectoral breakdown at roughly the two-digit level of the International Standard Industrial Classification of All Economic Activities (ISIC), resulting in 33 sectors. The OECD ICIO contains information on trade by sector, including services industries. Moreover, for China the database provides differentiated IO tables for four segments of the economy: production for domestic consumption, ordinary exporters, processing exporters, and services producers (exports and domestic sales). This feature allows us to capture the Chinese economy in great detail and to pay particular attention to the role of the processing segment. Alike all other available international IO databases, the OECD ICIO Database does not have information on actual bilateral IO coefficients. These coefficients are imputed from national IO 
tables based on a proportionality assumption. Accordingly, a sector's usage of a certain intermediate input is split between trade partners according to their respective shares in total imports of this particular intermediate good. For China's segments, customs data on imports by firm type (domestic, processing, non-processing) is used to obtain import shares specific to these production modes.

Data on bilateral tariffs are taken from UNCTAD's TRAINS database. We use effectively applied tariffs at the six-digit level of the Harmonized System (HS) goods classification and aggregate them to the OECD ICIO sectoral level using import values from the Comtrade Database as weights.

\subsection{Expenditure Shares, Cost Shares, and Sectoral Dispersion Parameters}

Firms' and consumers' first-order conditions with respect to intermediate, respectively, final goods demand for sectoral composites together with the Cobb-Douglas structure of the model imply that the model parameters, $\alpha, \beta$, and $\gamma$, can in theory be directly identified from observable expenditure and cost shares provided in IO tables. In practice, two additional issues need to be dealt with. First, we use sectoral tariffs to convert expenditures to purchaser prices, since the IO tables in the OECD ICIO Database are valued in producer prices. Moreover, to ensure that the model's equilibrium conditions hold in the data, we treat changes in inventory holdings as an intertemporal transfer augmenting income, alike trade deficits. Hence, our calibration perfectly matches production values, sectoral bilateral trade flows for final and intermediate goods, trade surpluses and the cost shares for intermediates (net of tariffs), as well as the tariff structure in 2000. We calculate value added and income by applying the equilibrium conditions of the model. Online Appendix D provides more details.

For the sectoral dispersion parameters we use the estimates of Caliendo and Parro (2015) and apply them to our slightly more aggregated sector classification in a way similar to Costinot and Rodríguez-Clare (2014). Due to the lack of data on ad-valorem trade costs for services, similar estimates of sectoral trade elasticities for services sectors are not available. Instead, we rely on an average value obtained by Egger et al. (2012), who estimate a trade cost elasticity for services of 4.96 based on a structural gravity model with one goods and one service sector. Column (1) of Table A.4 in the Appendix lists by sector the elasticities used in our main specification. We conduct simulations with alternative sets of estimates for $\theta$ to analyze the sensitivity of our results with respect to this choice. 


\section{China's Production Fragmentation and Networks in the 2000s}

China's accession to the WTO in 2001 was a major trade shock. It is widely believed that it significantly changed global sourcing structures and has spurred the formation of production networks with China. In the second half of the 1990s, China's exceptional export growth was accompanied by a decline in domestic value added content, signaling China's increasing participation in global value chains. In the early 2000s, however, this trend was reversed and by 2007 the foreign content share was back down to the level of 1996. Thereby, China defied the global trend of gradually declining domestic content shares. As Koopman et al. (2012) and Kee and Tang (2016) have argued, this trend reversal was at least partly linked to the asymmetric effect of China's WTO entry on processing and ordinary exporters. With import prices falling for ordinary exporters but not for processing exporters, the former substituted domestic with foreign value added. The corresponding decline in production costs, in turn, improved their competitiveness over foreign sources as suppliers to Chinese processing firms, who substituted foreign inputs with domestic ones.

The pattern of changes in DVA and VAX ratios across China's economic segments corroborates this argument. Fig. 1 shows that the increase in the DVA ratio at the country level (upper left panel) was spurred by the processing segment (upper right panel). The DVA ratios of ordinary exporters and services producers, who benefited from cheaper access to foreign intermediates, declined. The concurrent decline in the processing zones' VAX ratio, in turn, provides evidence that the additional domestic value added in its exports was sourced from domestic non-processing firms. China's domestic producers thus exported greater amounts of value added indirectly through the processing firms. The increase in the VAX ratio of Chinese service producers is a case in point.

To gauge the bilateral dimension of production sharing with China, we document salient features of supply networks involving China in the year 2000 and changes occurring over time using the measures developed in Section 2.2. Online Appendix F provides a thorough discussion. Averages of all network measures are presented in Table F.1.

Taking the perspective of downstream sectors in China, we first describe the relative importance of domestic and foreign suppliers of upstream value added. Across downstream sectors in China we find that domestic value added is by far the most important input; the (weighted) average share of 
Figure 1: VAX Ratio and DVA Ratio of China's Export Segments
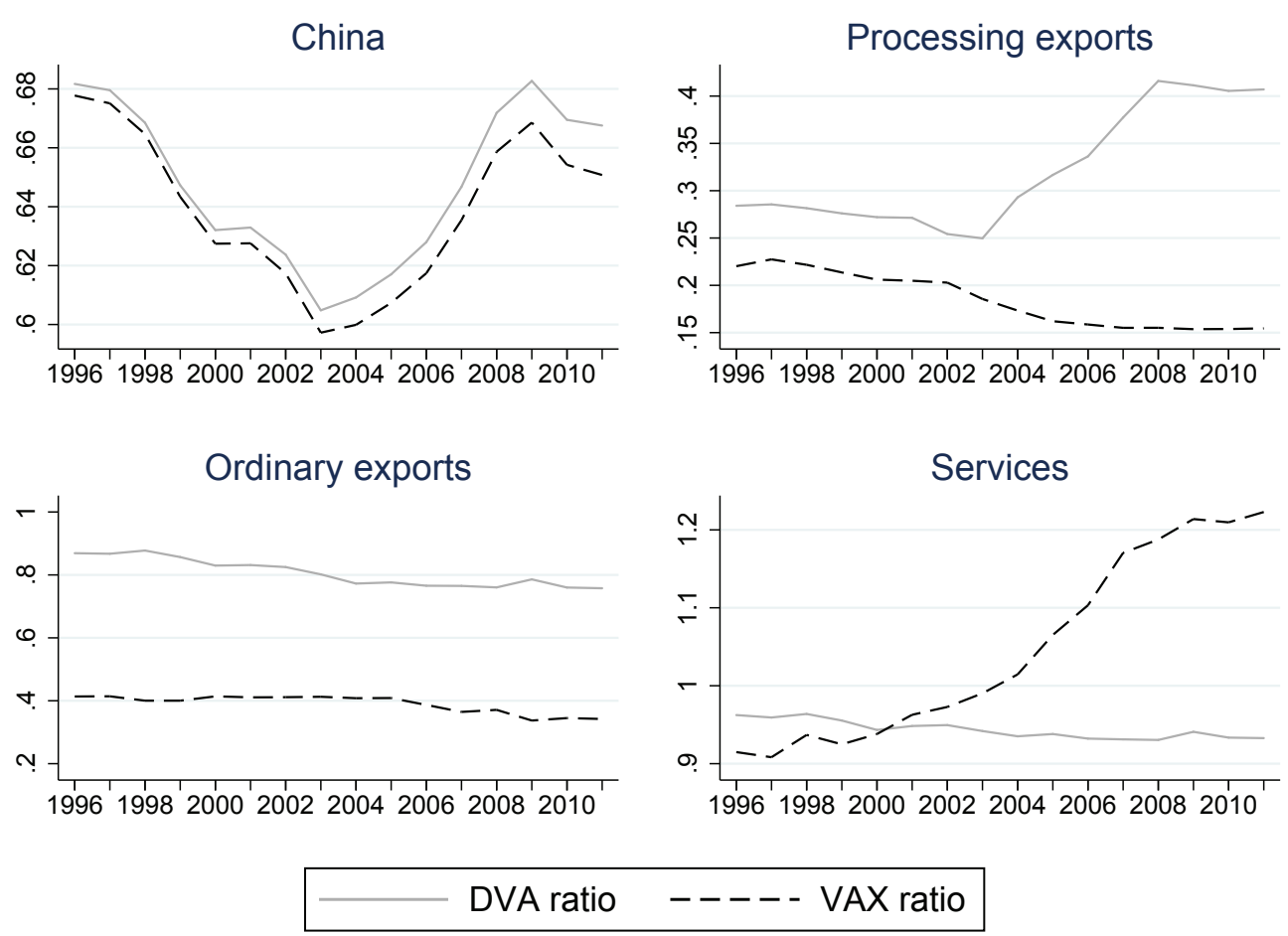

Note: The figure shows DVA and VAX ratio for China and its segments computed based on the methodology developed by Koopman et al. (2014) and the OECD's ICIO Database.

domestic in total upstream value added processed in China is $90 \%$. Among foreign sources, countries nearby China stand out. Japan accounts for the largest average foreign share (1.9\%), South Korea and Taiwan rank fourth and fifth. For all of China's supply networks, the correlation between network strength and distance is -.2. Besides proximity, country size also matters: The United States, RoW, and Germany also account for sizeable shares. There is substantial heterogeneity in the relative importance across sectors, as well as between China's processing zones and the rest of its economy. In the processing zones, foreign value added shares are considerably larger. Around $15(10,5) \%$ of all upstream value added entering final goods production in China's processing zones stems from Japan (the United States, South Korea). Firms in the processing zones also experienced completely different trends than the rest of China between 2000 and 2007. In accordance with the 
Figure 2: Change in China's Foreign Supply Networks: Electronics (ISIC 31)
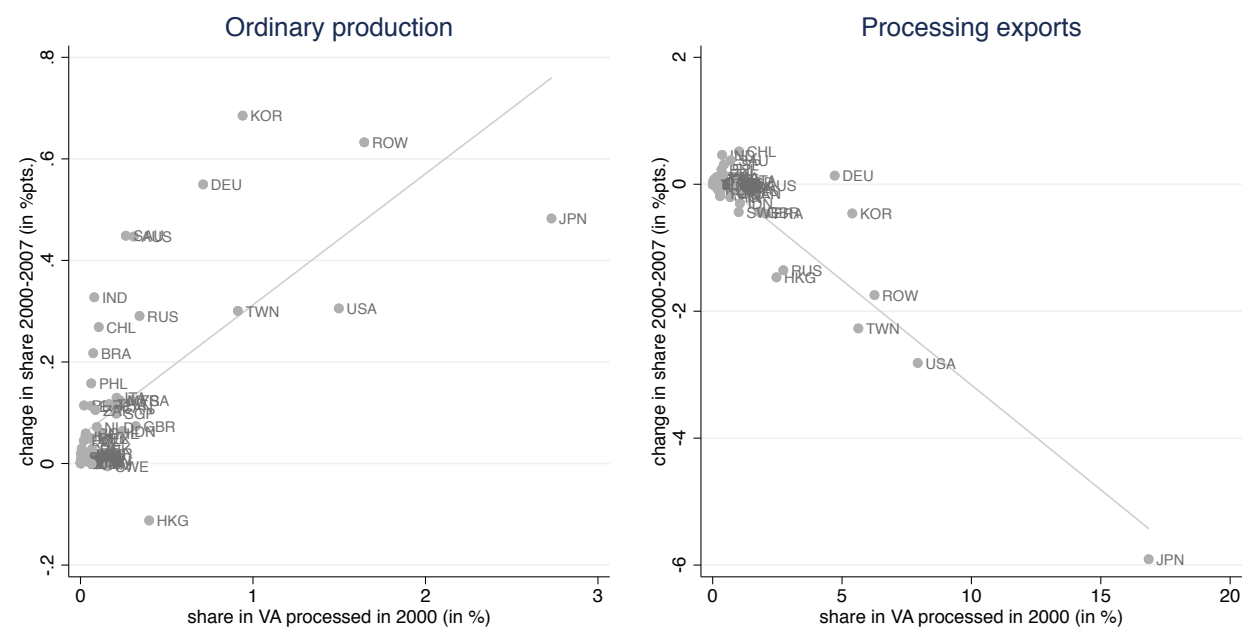

Note: The figure plots changes in foreign supply networks as defined in Eq. (12) of China's sectors producing under the export-processing regime (right panel) and under the ordinary regime (left panel) against the initial values in 2000. Calculations are based on the OECD's ICIO Database. The gray line shows a linear prediction.

aggregate value added content measures, we find that all sectors engaged in processing exports increased their reliance on domestic suppliers, whilst the share of domestic upstream value added in ordinary production went down.

Fig. 2 shows the corresponding changes in the relative importance of foreign sourced value added, exemplary for the Electronics sector under the ordinary (left panel) and the processing regime (right panel). The figure plots the change in network strength against the initial value in 2000, revealing a strong correlation. In ordinary production, domestic upstream value added was substituted for primarily with value added from the most important partners, as measured by initial network size. Conversely, the most important foreign source countries for China's processing firms experienced the strongest declines as domestic sourcing became more dominant. This strong correlation, which we also find for other networks (shown in Table F.1), is consistent with a non-linear, amplified response of trade in upstream production stages to trade cost changes as put forward by Yi (2003). The rank correlation between initial network strength and the change therein lies between .6 and .7 for the different networks (see the last row of Table F.1). 
Next, we take the perspective of downstream sectors in foreign countries to analyse the relative importance of China as a source of upstream value added. Between 2000 and 2007, China gained in importance as a value added source across a wide range of countries. South Korea stands out among the larger economies, both in terms of initial network strength and the change. Small Asian economies like Vietnam, Cambodia, Hong Kong, and Taiwan on average had the strongest supply networks with China initially and also experienced the strongest increases (see columns (3) and (4) of Table F.1). We also find, again, that initial network strength is strongly negatively correlated with distance, and growth in network strength correlates positively with the initial level - underscoring the increasing dominance of regional production networks for international production sharing as put forward by Baldwin and Lopez-Gonzalez (2015).

\section{Counterfactual Analysis: China's WTO Accession}

To analyze how China's WTO entry contributed to the rise in domestic content of China's exports, the strengthening of production networks with its neighboring countries, and the increase in global production fragmentation, we now turn to counterfactual analysis.

\subsection{Implementation of China's WTO Entry in the Counterfactual Analysis}

China's accession to the WTO entailed tariff cuts with all WTO trade partners. Depending on the product category, these were applied immediately upon accession or phased in after a (bilaterally) specified period of time; mostly by 2003, for some product categories by 2005, and in some cases as late as 2006 (WTO, 2001). Table A.2 shows the magnitude of the tariff cuts for the countries in our sample. The cuts were substantial, but very heterogeneous across countries; China had to drastically cut its tariffs on imports from Argentina and Brazil, where initial levels were also high, as well as on imports from Hungary, Canada, the US, Cambodia and Thailand, amongst others. On the other hand, import tariffs on goods from China decreased most strongly for some Eastern European countries (Romania, Hungary, Croatia and Slovenia) and for the emerging economies of India, Mexico, and Thailand. As regards sectoral heterogeneity, Table A.3 shows that Chinese tariff cuts on the import side were particularly deep in "Agriculture and fishing," "Motor vehicles," and "Food, beverages and tobacco." 
In our main specification, we simulate China's WTO accession by changing its inward and outward tariff rates with respect to all other countries to the most favored nation (MFN) rates in 2007, if these were lower than the applied tariffs in $2000 .{ }^{5}$ We take account of the fact that China's export processing firms enjoyed duty-free imports before the WTO accession by holding their import tariffs constant at zero. We chose 2007 as counterfactual year because by then all tariff cuts had been phased in.

Beyond tariff cuts, accession to the WTO also entails reductions in NTBs pertaining, for example, to import quotas, technical barriers to trade, sanitary and phytosanitary measures, actions against anti-dumping, intellectual property rights, a dispute settlement mechanism or the protection of foreign investment with the WTO's Agreement on Trade-Related Investment Measures (TRIMs). Many of these provisions were also phased in after 3 to 5 years (WTO, 2001). Moreover, Handley and Limão (2017) and Pierce and Schott (2016) show that, in the case of China and the United States, the reduction in TPU was quantitatively more important than tariff cuts. Given the many challenges involved in quantifying the effects of WTO entry on NTBs, we focus mainly on the tariff cuts. ${ }^{6}$ However, as a robustness check we also present and discuss results from a counterfactual experiment where we include estimated changes in NTBs (including potential effects of TPU) obtained from a gravity equation (see Section 5.3.1).

\subsection{Results: The Effects of China's WTO Entry}

\subsubsection{Aggregate Trade and Welfare Effects}

Our counterfactual analysis predicts that world real exports increased by $3 \%$ due to the tariff cuts associated with China's WTO entry, as shown in Table 1, column (1). A driving force was China's export growth of $43 \%$, but sizeable effects can also be attributed to Argentina (61\%) and Brazil (24\%), the two countries whose outward tariffs with China declined most.

\footnotetext{
${ }^{5}$ The UNCTAD TRAINS database distinguishes between MFN and preferential tariff rates. This allows us to single out tariff cuts stemming from the WTO accession and discard tariff cuts due to reductions in preferential tariff rates.

${ }^{6}$ As regards quantifying TPU, the United States is a special case where the tariffs for times of non-normal trade relationships with China were well defined. Had the United States' congress voted to revoke China's temporary MFN status, tariffs would have gone back up to the levels specified in the Smooth-Hawley Act of 1930. For other countries, however, little to nothing is known about tariff levels in times of non-normal relationships and quantifying cost equivalents of TPU is much harder.
} 
Table 1: Aggregate Trade Effects

\begin{tabular}{|c|c|c|c|c|c|c|}
\hline \multirow{3}{*}{ Country } & \multicolumn{3}{|c|}{ CF: Tariffs } & \multicolumn{3}{|c|}{ Actual Changes 2000-07 } \\
\hline & $\widehat{E}$ & $\widehat{V A X / E}$ & $\overline{D V A / E}$ & $\widehat{E}$ & $\widehat{V A X / E}$ & $\overline{D V A / E}$ \\
\hline & $\%$ & $\% \mathrm{pts}$ & $\%$ pts & $\%$ & $\%$ pts & $\%$ pts \\
\hline $\mathrm{CHN}$ & 43.2 & 1.30 & 1.41 & 291.1 & 0.8 & 1.5 \\
\hline Processing exports & 25.4 & -0.68 & 2.14 & 286.5 & -5.1 & 10.5 \\
\hline Ordinary exports & 79.1 & -1.87 & -4.13 & 351.5 & -5.0 & -6.5 \\
\hline Services & 28.1 & 8.72 & -1.11 & 234.0 & 23.2 & -1.2 \\
\hline ARG & 61.5 & -3.41 & -3.53 & 73.1 & -7.3 & -7.5 \\
\hline BRA & 23.5 & -0.65 & -0.69 & 142.5 & -0.2 & 0.0 \\
\hline VNM & 7.6 & -3.44 & -3.47 & 167.4 & -6.5 & -6.5 \\
\hline PER & 4.5 & -0.20 & -0.19 & 204.6 & -1.7 & -1.6 \\
\hline USA & 4.0 & 0.24 & -0.03 & 25.9 & 1.3 & -1.1 \\
\hline MEX & 2.9 & 0.05 & 0.01 & 35.1 & 2.6 & 2.6 \\
\hline IND & 2.8 & -0.47 & -0.46 & 256.6 & -7.5 & -7.2 \\
\hline $\mathrm{HKG}$ & 2.4 & -0.36 & -0.36 & 44.6 & -3.4 & -3.5 \\
\hline KHM & 2.3 & -0.25 & -0.25 & 157.7 & -2.8 & -2.8 \\
\hline WLD & 3.2 & -0.11 & -0.15 & 76.5 & -1.9 & -2.4 \\
\hline
\end{tabular}

Note: The table shows aggregate real export changes $(\widehat{E})$, changes in the value added export to export ratio $\left(\overline{V A X / E}=\frac{V A X^{\prime}}{E^{\prime}}-\frac{V A X}{E}\right)$ and the ratio of domestic value added in exports $\left(\overline{D V A / E}:=\frac{D V A^{\prime}}{E^{\prime}}-\frac{D V A}{E}\right)$ for the counterfactual scenario of tariff reductions associated with China's WTO entry (columns 1-3) and observed changes in the data (columns 4-6). Only the 10 countries with the largest trade effects and the world aggregate are displayed.

Countries close to China, as well as the United States, Mexico, and Peru, also experienced sizeable export growth. We find positive but small or even slightly negative effects for most of the European economies. Breaking China up into its segments, we find that the increase in processing exports was only one third of the increase in ordinary exports and similar to the increase in services exports. This is consistent with the fact that processing exporters, in contrast to ordinary exporters, did not benefit from a decline in input costs due to import tariff cuts.

Furthermore, the results show that China's WTO entry spurred production fragmentation as measured by the VAX ratio or the DVA ratio for countries other than China. At the world level, the VAX (DVA) ratio decreased by .11 (.15) percentage points. For China, we find differential effects in line with the pattern observed in the data. Lower tariffs spurred production fragmentation for ordinary exporters and services firms, whose DVA ratio decreased 
by 4.1 and 1.1 percentage points. Processing firms, on the other hand, turned to the increasingly competitive domestic inputs, leading to a higher DVA ratio (2.1 percentage points) for the processing segment and higher indirect value added exports (VAX ratios) for China's domestic producers and services firms. Aggregating to the country level, we find that both China's DVA and VAX ratio increased (1.4 and 1.3 percentage points, respectively). Consistent with the pattern in the data (cp. Fig. 1 and Table A.1) and the findings of Brandt and Morrow (2017), this increase in the aggregate degree of production fragmentation owes also to the between-sector reallocation toward the non-processing and services segment, which had much higher DVA (and VAX) ratios to begin with.

How big are these predicted changes in relation to the actual changes that occurred between 2000 and 2007? The answer to this question depends on the particular numbers at which we look. At the world level, we find that China's WTO entry explains about $6 \%$ of the decline in the world VAX and DVA ratio. These are sizeable effects if one takes into account that the only difference between the baseline and the counterfactual is the tariff structure of a single country. The counterfactual experiment does not consider growth in world GDP or growth in China due to anything other than the trade cost changes, which explains why the counterfactual changes in total world exports or China's exports replicate only a small fraction of the actual change (about $4 \%$ for the world, 15\% for China). As regards China's structural changes, for example in the pattern of value added flows, the trade cost changes associated with its WTO entry go a long way in explaining the changes observed in the data. We find that the counterfactual changes fully reproduce the observed pattern of differential changes in VAX ratios and DVA ratios across and within China's segments. At the country level, the tariff changes suffice to explain $94 \%$ of the increase in the DVA ratio.

China's WTO entry also explains sizeable shares of the actual changes in DVA and VAX ratios in countries nearby, as well as in Argentina, Brazil, and the United States. Notably, the model correctly predicts the differential changes in the United States' DVA and VAX ratio, suggesting that it can at least partly be explained by a a shift in the composition of exports towards value-added-intensive services and a relative decline of the North American production network in the face of new trading opportunities with China. The latter implies lower imports from the United States' neighboring countries and lower amounts of reimported domestic value added, which may decrease the DVA ratio even if value added exports over exports increase. 
Table 2: Changes in the Value Added Composition of China's Exports (in \%)

\begin{tabular}{lccc}
\hline & $\begin{array}{c}\text { Share in abs. export growth } \\
\text { Share in exports } \\
\text { Data: } \\
\text { Counterfactual: } \\
\text { Tariffs }\end{array}$ \\
\hline Domestic VA & 63.2 & 64.9 & 67.8 \\
Foreign VA & 29.3 & 26.1 & 25.6 \\
Returned dom. VA & 0.1 & 0.2 & 0.1 \\
Double counting & 6.6 & 8.3 & 6.2 \\
\hline
\end{tabular}

Note: The table shows for different value added components as defined in Koopman et al. (2014) shares in total exports in $2000, \frac{V A_{\text {type }}}{E} * 100$, and shares in total absolute export growth $\left(\frac{\Delta V A_{\text {type }}}{\Delta E} * 100\right)$.

Quantitatively, the farther away we move from China, the less of the actual developments in country-level variables is explained. However, as we show below, at a more disaggregated level we find that our simulated effects of China's WTO entry align well with the changes in the bilateral and sectoral pattern of trade in value added with many countries.

Next, we use Koopman et al. (2014)'s decomposition method outlined above to analyze how China's WTO entry affected the composition of its exports. Table 2, column (1) shows the share of China's total export value that accrues to domestic, foreign, returned domestic, or double-counted value added. Column (3) shows the counterfactual share of the absolute change in total exports that can be attributed to the different components. Column (2) shows the corresponding values observed in the data between 2000 and 2007. As discussed above, domestic value added gained in importance relative to foreign value added over this time period, but so did double-counting and reimports of domestic value added. Our counterfactual experiment yields the same pattern, except for the share of double-counted value added.

To assess the welfare implications of China's accession to the WTO, we look at changes in real income as given in Eq. (B.12). Table 3 shows welfare changes for countries ranging among the 5 (3) most positively (negatively) affected, as well as for China and the United States. China ranks second among the 64 countries in our analysis. The predicted real income increase is $1.4 \%$, and it was realized despite sizeable losses in tariff revenue $(37 \%)$. The other countries with sizeable positive effects are China's neighbors, as 
Table 3: Income and Welfare Effects (in \%)

\begin{tabular}{cccccccccccc}
\hline Country: & ARG & CHN & VNM & KOR & KHM & BRA & USA & JPN & MEX & BRN & CHL \\
\hline Rank $\widehat{W}$ & 1 & 2 & 3 & 4 & 5 & 6 & 9 & 14 & 62 & 63 & 64 \\
$\widehat{w / P}$ & 1.1 & 1.8 & 1.3 & 0.2 & 0.7 & 0.4 & 0.1 & 0.0 & -0.1 & -0.0 & -0.2 \\
$\widehat{R}$ & 36.7 & -17.8 & -6.5 & 20.1 & -1.6 & 13.1 & 1.9 & 0.7 & -1.3 & -0.7 & -2.4 \\
$\widehat{W}$ & 1.4 & 1.4 & 0.8 & 0.7 & 0.5 & 0.5 & 0.1 & 0.0 & -0.1 & -0.2 & -0.2 \\
\hline
\end{tabular}

Note: The table shows counterfactual changes in real wages, tariff income, and welfare (real income) in rows (2)-(4). Only the 5 (3) countries with the largest positive (negative) changes as well as China, Japan and den U.S. are shown. Rank $\widehat{W}$ denotes countries' ranks in terms of welfare effects.

well as Argentina and Brazil. We find positive but very small welfare effects for the United States and small negative welfare effects for twelve countries, primarily middle-income countries in Europe, and low- and middle-income countries in Africa and the Americas.

\subsubsection{Effects on Production Networks}

China's WTO accession facilitated easier access to inputs for Chinese producers. The sectoral and bilateral heterogeneity of tariff changes suggests that input suppliers were differentially affected and the sectoral and global interlinkages make it hard to predict ex-ante how value added flows change as a consequence of trade cost changes. We use our measures of network strength to shed light on the question of which countries and sectors intensified their production linkages with China.

Our counterfactual changes in supply networks imply that China's WTO accession can explain key trends in the supply network structure involving China. Qualitatively, our counterfactual experiment is able to repeat the differential change in the sourcing structure of the export-processing and ordinary production segments as well as the relative changes of China's share in upstream value added across different final goods producing locations. Fig. 3 plots for all Chinese downstream sectors in the export-processing (dark gray dots) and ordinary segment (light gray dots) the actual changes against the counterfactual changes. For $80 \%$ of China's exporting sectors, the model correctly differentiates positive and negative changes and also reproduces quite well the relative order of changes for the processing exporters.

Fig. 4 zooms into the "Other Equipment" and "Electronics" sectors and 
Figure 3: Counterfactual vs. Actual Changes in Intra-China Supply Networks

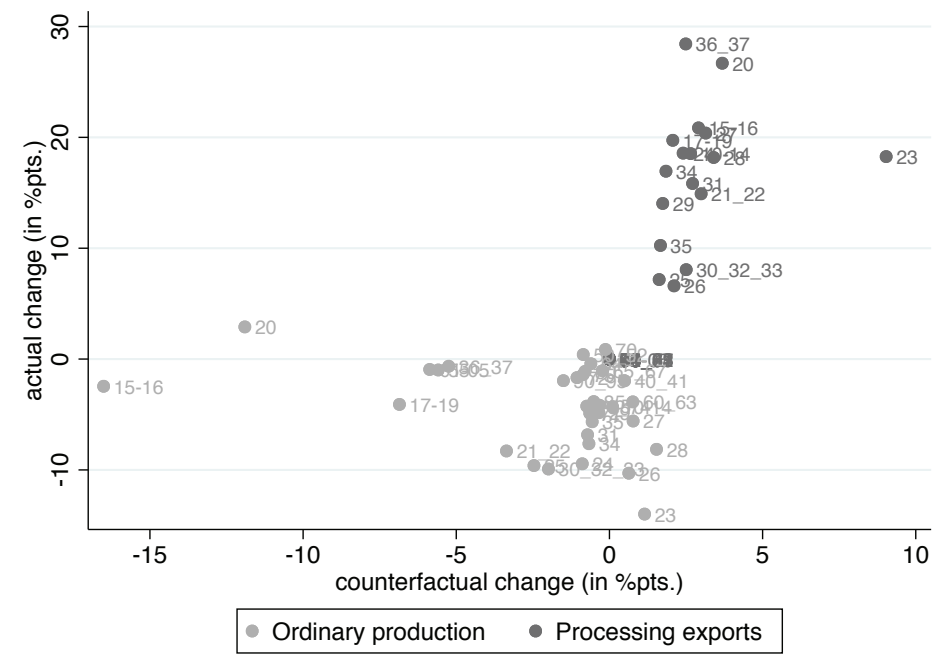

Note: The figure plots observed changes (2000-2007) vs. counterfactual changes in supply networks of Chinese value added source sectors with the aggregate processing/ordinary production segments in China. Labels denote source sectors in ISIC Rev. 3, see Table A.4 for sector descriptions.

describes how well we predict China's share of upstream value added processed by these sectors in different countries. Black dots correspond to the ten foreign countries most affected by China's WTO entry in terms of real wage changes. We find a positive correlation between actual and predicted changes which is particularly strong for the countries most affected by China entering the WTO. Our counterfactual experiment replicates the fostering of the regional production network in East Asia observed in the data (see also Fig. F.4). Note, however, the different scales on the axes. The counterfactual changes match the pattern qualitatively, but not quantitatively.

\subsection{Robustness}

In this section, we present robustness checks pertaining to the inclusion of estimated NTB effects, the choice of values for the sectoral dispersion parameters, and other modeling assumptions.

\subsubsection{Non-Tariff Barriers}

As discussed in Section 5.1, our counterfactual analysis could underpredict the impact of China's WTO accession since we disregard potential effects 
Figure 4: Counterfactual vs. Actual Changes in Foreign Supply Networks with China
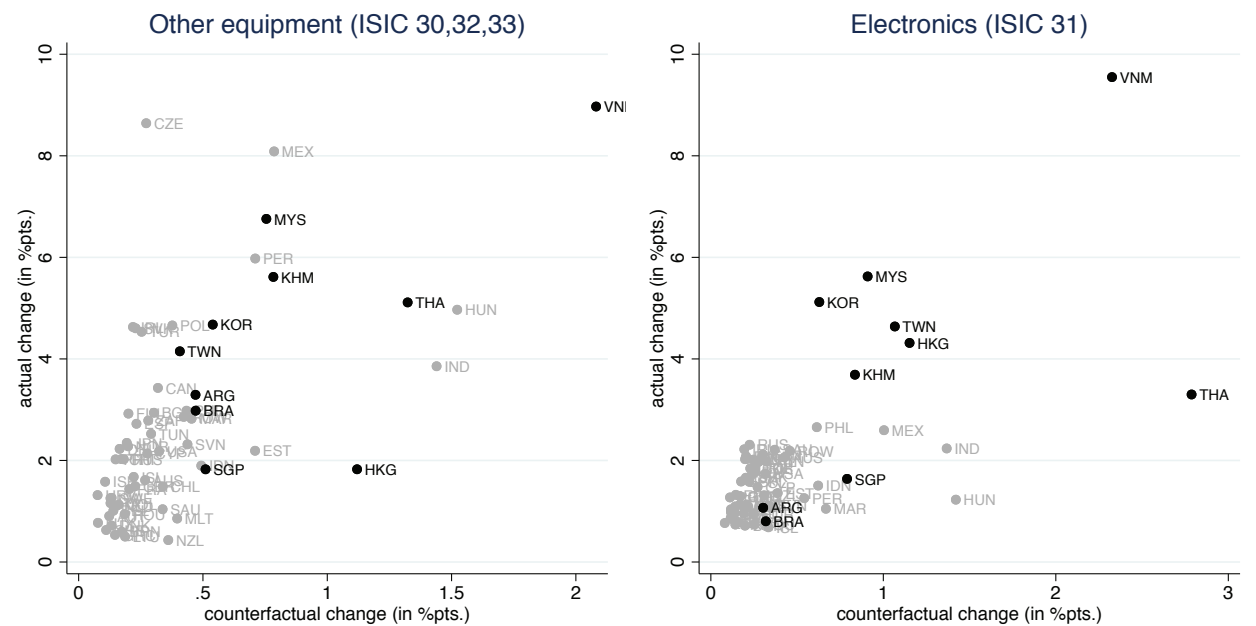

Note: The figure plots observed (2000-2007) vs. counterfactual changes in supply networks of the Other equipments (left panel) and Electronics sector (right panel) in foreign countries with China. Black dots indicate the 10 countries most affected by China's WTO entry in terms of real wages.

of reductions in NTBs. To quantify these effects, we estimate sectoral cost equivalents of WTO membership based on a gravity equation. This approach is all-encompassing in the sense that the WTO dummy in the gravity equation captures the effects of a plethora of hard-to-quantify policy measures ranging from import quotas to TPU to investment protection. A drawback of the approach is that it is not clear which of the policy changes are actually responsible for the observed effects - and that we measure average trade cost changes across all countries entering the WTO during the time period spanning our estimation sample, rather than an effect that is specific to China. ${ }^{7}$

Our panel estimation approach follows the gravity literature. We regress sectoral trade flows on dichotomous trade cost proxies (WTO, preferential trade agreement (PTA), and common market or customs union (CCU) membership). ${ }^{8}$ Following Baier et al. (2014), we include two lags of these dummy

\footnotetext{
${ }^{7}$ To avoid circular causality, our estimated average WTO effects do not include the effect of China's WTO entry on its trade costs.

${ }^{8}$ For a survey of the literature on the estimation of NTBs in structural gravity models, see Head and Mayer (2014). Data on trade agreement membership stems from Baier \& Bergstrand's database accessible via https://www3.nd.edu/ jbergstr/.
} 
variables to allow for effects to phase in. We estimate parameters sector-bysector and include exporter-time and importer-time fixed effects to capture time-varying country-sector-specific factors (e.g. market size or technology), and country-pair fixed effects to control for all time-invariant variables that are specific to the country pair and a given sector (e.g. distance). This fixed effect strategy has emerged as common practice in the literature to address concerns about endogeneity of the choice of joining a trade agreement, reducing such concerns to the timing of entry, (see, e.g., Baier and Bergstrand, 2007; Dutt et al., 2013; Yotov et al., 2016; Mayer et al., 2018). Trade flows are divided by $\left(1+\tau_{i n}^{j}\right)^{-\theta^{j}}$ to purge them from the effects of tariffs in accordance with the trade share equation (1). Thus, the WTO dummies capture only non-tariff effects of WTO membership.

Table A.4 shows the estimated changes in tariff equivalents of joint membership in the WTO (in a PTA, in a CCU) based on a Poisson panel estimation for the years 1996, 2001, 2006, 2011. ${ }^{9}$ The NTB changes implied by WTO membership are very heterogeneous across sectors. Especially the "Rubber and plastics" and "Motor vehicles" sectors seem to benefit from removals of import quotas and other NTBs. We find sizeable effects also for "Agriculture, fishing," and "Basic metals." For "Agriculture and fishing," for example, the cumulated estimated coefficient is .66, implying a $e^{0.66}-1=.93$ or $93 \%$ increase in agricultural trade among WTO members, which is equivalent to the effect of a $7.8 \%$ tariff reduction. In other sectors, WTO membership has been less effective in bringing down NTBs, as indicated by the insignificant estimates. In "Other minerals" and "Other manufacturing" we even find positive, significant cost changes. For the service sectors we find no significant cost decreases, and positive and significant effects for some. Hence, our estimates indicate that WTO membership does not spur service trade integration and, possibly, even favors trade in goods at the expense of less services trade.

In our model, the described NTB effects act as changes in iceberg trade costs. In the counterfactual experiment, we now change China's inward and outward trade costs by the estimated amounts - in addition to the tariff cuts. We run the simulation twice, one time including all cost effects that are significant at the $10 \%$ significance level and one time without the positive and

\footnotetext{
${ }^{9}$ We use the Poisson panel estimation routine developed by Tom Zylkin. See Larch et al. (2017) for details. Detailed estimation results can be found in Tables G.1 and G.2.
} 
Table 4: Summary of Robustness Checks

\begin{tabular}{|c|c|c|c|c|c|c|c|c|}
\hline & \multicolumn{2}{|c|}{ World } & \multicolumn{6}{|c|}{ China } \\
\hline & $\begin{array}{l}\widehat{E} \\
\%\end{array}$ & $\begin{array}{l}\overline{D V A / E} \\
\% \mathrm{pts}\end{array}$ & $\begin{array}{c}\text { Total } \\
\widehat{E} \\
\%\end{array}$ & Total & $\begin{array}{r}\text { ProcE } \\
L\end{array}$ & $\begin{array}{l}\text { NormE } \\
\% \text { pts } \\
\% \text { pts }\end{array}$ & Services & $\begin{array}{l}\widehat{W} \\
\%\end{array}$ \\
\hline a) Main simulation: Tariffs & 3.19 & -0.15 & 43.23 & 1.41 & 2.14 & -4.13 & -1.11 & 1.39 \\
\hline \multicolumn{9}{|l|}{ NTB effects } \\
\hline b) Tariff cum NTB scenario & 4.24 & -0.29 & 58.25 & 0.82 & 2.51 & -5.72 & -1.84 & 2.68 \\
\hline c) No positive NTB effects & 4.31 & -0.29 & 59.31 & 0.77 & 2.43 & -5.83 & -1.88 & 2.74 \\
\hline \multicolumn{9}{|l|}{ Trade elasticities } \\
\hline d) Broda \& Weinstein (2006) & 1.03 & -0.07 & 14.19 & 0.67 & 0.79 & -2.35 & -0.36 & 0.31 \\
\hline \multicolumn{9}{|l|}{ e) Egger et al. (2012) } \\
\hline$\theta_{\text {Goods }}=6.98, \theta_{\text {Services }}=4.96$ & 2.65 & -0.13 & 36.90 & 1.07 & 2.10 & -5.24 & -1.35 & 1.03 \\
\hline f) $\theta=5$ for all sectors & 1.55 & -0.09 & 21.33 & 0.74 & 1.16 & -3.54 & -0.79 & 0.44 \\
\hline \multicolumn{9}{|l|}{ Model \& data } \\
\hline $\begin{array}{l}\text { g) No processing segment } \\
\text { new baseline }\end{array}$ & -0.78 & 0.36 & -13.85 & 7.98 & 5.60 & 0.14 & 0.11 & 0.31 \\
\hline $\begin{array}{l}\text { h) No processing segment } \\
\text { WTO entry }\end{array}$ & 3.49 & -0.28 & 55.82 & -3.13 & -0.86 & -4.23 & -1.17 & 1.34 \\
\hline i) One aggregate China & 3.98 & -0.08 & 56.27 & -4.60 & & & & 2.04 \\
\hline $\begin{array}{l}\text { j) Equal trade shares } \\
\text { final and interm. goods }\end{array}$ & 3.97 & -0.19 & 56.03 & -4.21 & & & & 2.03 \\
\hline
\end{tabular}

Note: The table shows aggregate real export changes $(\widehat{E})$, changes in the ratio of domestic value added in exports $\left(\overline{D V A / E}:=\frac{D V A^{\prime}}{E^{\prime}}-\frac{D V A}{E}\right)$ and real income changes $(\hat{W})$ for various robustness checks pertaining to the inclusion of $\mathrm{NTB}^{E^{\prime}}$ effects, trade elasticities and model assumptions. For easier comparison, the first row shows the results of the main specification (tariffs-only scenario). Only the world aggregate (columns 1-2) and China and its segments (columns 3-8) are displayed.

significant effects. Rows (b) and (c) of Table 4 show, respectively, the results for export growth and changes in the DVA ratio for the world aggregate and China and its segments.

Including estimated cuts in NTBs in our simulation yields trade effects for China and the world that are 30-40\% larger than when considering tariff cuts only. The world DVA ratio is predicted to fall by .29 percentage points. So the tariff-cum-NTB scenario explains $12 \%$ of the actual change in global production fragmentation. Furthermore, we obtain counterfactual changes at the more disaggregate level that are much closer to the observed 
ones quantitatively. The diverging pattern in the DVA ratios of China's segments and the overall increase prevails. The predicted real income gain for China is also bigger (about 2.7\%). These findings are not sensitive to the way estimated positive sectoral NTB effects are treated. To summarize, the predictions from the tariffs-only and the tariffs-cum-NTB scenarios are qualitatively similar, while the NTB scenario does a better job in explaining the observed changes quantitatively.

\subsubsection{Trade Elasticities}

Next, we analyze the robustness of our findings with regard to the calibration of the sectoral dispersion parameters, $\theta$. The gravity equation (1) implies that $\theta$ can be identified as the elasticity of trade with respect to trade costs. Our main specification uses the structural estimates of Caliendo and Parro (2015), which are identified under the assumption that tariffs are exogenous to trade flows conditional on sector-country-pair fixed effects. The extant literature provides ample alternative estimates for trade cost elasticities. We redid our exercise using the product-level estimates of Broda and Weinstein $(2006),{ }^{10}$ an aggregate elasticity for goods trade of $\theta_{\text {Goods }}=6.98$ obtained by Egger et al. (2012) (from whom we also use the aggregate estimate of the service trade elasticity $\theta_{\text {Services }}=4.96$ in all our specifications) and the commonly used rule-of-thumb value $\theta=5$ for all sectors. Table 4 , rows (d)(f), present results from these sensitivity checks. We find qualitatively very similar results; all model calibrations produce the same differential changes in the DVA ratio across China's segments as our main specification (row a). In terms of magnitudes, the results obtained with aggregate elasticities from Egger et al. (2012) are similar to our main specification. Using Broda and Weinstein (2006)'s estimates or simply $\theta=5$ yields smaller effects throughout. Overall, these sensitivity checks suggest that the exact calibration of the trade elasticities is not essential for the qualitative results. They yield aggregate trade growth for China (the world) between 14 and 43\% (1 and $3 \%$ ) and welfare effects for China ranging between .3 and $1.4 \%$.

\footnotetext{
${ }^{10}$ Broda and Weinstein (2006) estimate a system of export supply and import demand equations using the methodology developed by Feenstra (1994). Identification rests on the assumption that after differencing export supply and import demand at the countrypair-product level across time and with respect to a reference country, shocks to demand and supply are uncorrelated. We aggregate the product-level estimates to our sector level using trade weights.
} 


\subsubsection{The Role of Processing Exporters}

The processing segment in China plays a crucial role in understanding the effects of China's WTO entry on local production chains, especially China's defiance of the global trend of declining domestic value shares in exports. To highlight the processing zones' role, we simulate China's WTO entry starting from a counterfactual baseline where the processing segment does not enjoy toll-free imports. To that end, we use the model to first simulate a new baseline by introducing import tariffs for the processing segment alike the rest of China. Row (g) of Table 4 presents the counterfactual changes from the actual baseline year 2000 to the counterfactual baseline. Intuitively, introducing import tariffs for the processing segment impedes production fragmentation as indicated by higher domestic value added ratios for China and the world as a whole. As input costs for the processing segment go up, China loses competitiveness in global markets. Hence, exports decline. Interestingly, China nevertheless experiences a welfare gain from such a policy $(.3 \%$ higher real income), which is driven by a sizeable increase in tariff revenues. Starting from this new baseline, we now simulate China's WTO entry. We find that without the processing zones' preferential tariff treatment, China's WTO entry would have spurred production fragmentation in all of its economic segments and in the aggregate, as indicated by the declining DVA ratios.

We also simulate China's WTO entry in a version of the model where we aggregate the differential IO structure for China to the national level, using a trade-weighted average import tariff for the aggregated China. This structure resembles the one typically used in international input output databases, such as the World Input Output Database or GTAP. Without the disaggregation of China's segments, the model can also not replicate the increase in the DVA ratio (row i). Next, we check the importance of differentiating trade shares across final and intermediate goods. This assumption is essential for calibrating the differential effect of trade cost changes on China's segments. For the quantitative effects, however, it does not seem to be crucial. When calibrating the model version with an aggregated China (used in row i) to match the same average trade shares across final and intermediate goods, we obtain almost identical results (see row $\mathrm{j}$ ).

\section{Additional Counterfactual Experiments}

To put the simulation results for China's WTO accession into perspective, we perform a series of additional experiments pertaining to changes in trade 
costs and other observed exogenous variables between 2000 and 2007. Table 5 summarizes the simulation results focusing on trade growth and changes in the DVA ratio for the world aggregate and China, as well as China's real income growth. For comparison, row (a) repeats the actual changes.

Trade cost changes. First, we quantify the effects of various global trade cost changes. Row (b) shows the counterfactual changes to a world with zero tariffs, starting again from the base year 2000. Eliminating all tariffs implies significant increases in exports for some regions, most prominently for non-processing China (113\%, not shown). World exports would rise by $24 \%$. At the same time, production fragmentation would be strengthened, as indicated by the significant drop in the DVA ratio for most regions, and by 3.9 percentage points in the world aggregate. Note, however, that China would defy the global trend also in a free trade scenario, again for the same reasons as in our main specification.

Second, we simulate the effects of all actual world-wide MFN and preferential tariff changes ocurring between 2000 and 2007. These tariff reductions are predicted to cause a 11\% increase in world exports and a 1.9 percentage points reduction of the world's DVA ratio (see row c). While China's tariff reductions in the wake of its WTO entry can explain around $6 \%$ of the increase in global production fragmentation, global tariff reductions in the same time period can explain around $77 \%$ of this trend. The pattern of a rising Chinese DVA ratio driven by the export-processing zones prevails. Ordinary exporting and services China again see a drop in their DVA ratios.

If we additionally consider the NTB reductions implied by the formation of and entries into trade agreements and the WTO,${ }^{11}$ we explain about 1.4 percentage points more of global export growth but little more of the globally observed trend in production fragmentation. Reductions of global transportation $\operatorname{costs}^{12}$ appear to have spurred global production fragmentation to a similar extent than global tariff changes (see row e). However, they cannot explain the diverging trends in the DVA ratios for China's processing

\footnotetext{
${ }^{11}$ See Section 5.1 for details on the estimation of cost equivalents. We capture the effects of all trade agreements reported in the Baier et al. (2014) database on trade costs between the 63 individual countries but not for pairs involving countries from the RoW.

${ }^{12}$ For transportation cost changes we use data on bilateral CIF/FOB margins from the OECD's ITIC database, provided at the HS 4-digit level. We convert them to ad-valorem equivalents and use trade flows from the COMTRADE database for the aggregation to the ISIC sector level.
} 
Table 5: Additional Counterfactual Experiments: Changes in Trade Costs, Technology, Demand, and Surpluses 2000 - 2007

\begin{tabular}{|c|c|c|c|c|c|c|c|c|}
\hline \multirow[b]{2}{*}{ Trade elasticities } & \multicolumn{2}{|c|}{ World } & \multicolumn{6}{|c|}{ China } \\
\hline & $\begin{array}{l}\widehat{E} \\
\%\end{array}$ & $\begin{array}{l}\overline{D V A / E} \\
\% \mathrm{pts}\end{array}$ & $\begin{array}{c}\text { Total } \\
\widehat{E} \\
\%\end{array}$ & Total & $\begin{array}{r}\text { ProcE } \\
L\end{array}$ & $\begin{array}{l}\frac{\text { NormE }}{V A / E} \\
\% \text { pts }\end{array}$ & Services & $\begin{array}{l}\widehat{W} \\
\%\end{array}$ \\
\hline a) Actual changes $2000-07$ & 76.46 & -2.41 & 291.11 & 1.47 & 10.53 & -6.47 & -1.21 & \\
\hline \multicolumn{9}{|l|}{ Trade cost changes } \\
\hline b) No more tariffs & 23.76 & -3.94 & 81.64 & 1.02 & 2.43 & -7.88 & -3.53 & 1.60 \\
\hline c) Global tariff reductions & 10.88 & -1.86 & 34.19 & 2.67 & 2.37 & -3.42 & -0.59 & 1.17 \\
\hline $\begin{array}{l}\text { d) All trade agreements } \\
\& \text { tariff reductions }\end{array}$ & 11.96 & -1.87 & 47.37 & 2.11 & 2.80 & -5.15 & -1.21 & 2.45 \\
\hline $\begin{array}{l}\text { e) Transportation cost } \\
\text { changes }\end{array}$ & 6.63 & -1.81 & 2.12 & -0.77 & -0.26 & -0.49 & 0.18 & 0.28 \\
\hline \multicolumn{9}{|c|}{ Changes in other exogenous variables } \\
\hline f) Technology $\beta$ & 2.66 & -2.11 & 4.20 & -0.62 & -0.01 & -1.67 & -1.75 & -0.04 \\
\hline g) Technology $\alpha, \beta, \gamma$ & -1.05 & -1.86 & -2.88 & 1.06 & 1.56 & -2.71 & -2.39 & -0.10 \\
\hline h) Surpluses \& inventory & 1.61 & -1.02 & 63.12 & 8.99 & 4.37 & 4.95 & 1.62 & -27.12 \\
\hline i) All changes & 19.57 & -7.26 & 104.49 & 3.52 & 5.95 & -8.39 & -4.08 & -24.37 \\
\hline
\end{tabular}

Note: The table shows aggregate real export changes $(\widehat{E})$, changes in the ratio of domestic value added in exports $\left(\widehat{D V A / E}:=\frac{D V A^{\prime}}{E^{\prime}}-\frac{D V A}{E}\right)$ and real income $(\widehat{W})$. Baseline year for all counterfactual scenarios is 2000, changes in exogenous variables in scenarios (c)-(i) refer to the period 2000-07. In (b) we set all tariffs to zero. In (c) we change 2000 tariffs to their 2007 levels for all countries, as observed in the TRAINS database. In (d) we use estimated ad-valorem equivalents of NTB changes from a gravity equation and simulate the effects of global entry into PTAs, CCUs, and the WTO. Data on transportation cost changes for (e) are obtained from the OECD ITIC database. In (f,g,h) we simulate, respectively, adjustments to new cost shares $\beta$, new cost and expenditure shares $\alpha, \beta, \gamma$, and new trade surplus and inventory levels as observed in the ICIO Database in 2007. Scenario (i) combines all exogenous changes from rows (d,e,g,h).

and ordinary exporters; these are lowered for all of China's exporters.

Regarding welfare effects, we find that China's real income gain associated with its WTO entry (1.4\%) exceeds the gain from global transportation cost and tariff reductions. China's real income gain due to all observed trade policy changes (including its own WTO entry) amounts to $2.4 \%$.

Other observed exogenous changes. We also quantify the effects of changes in other observable parameters that are exogenous in our model and may have influenced the pattern of trade and our measures of production sharing. For example, in the data we observe significant increases in the share 
of intermediate goods used in production, reflecting declining value added shares $\beta$. These changes are consistent with the notion that the cost of outsourcing (domestically or abroad) have been declining over time thanks to lower communication costs and enhanced intellectual property rights protection. Greater reliance on intermediate inputs is expected to spur trade as well as foreign value added content, as part of them will be sourced from abroad. Row (f) presents changes to a counterfactual scenario where we have changed the (exogenous) value added shares for all countries and sectors to their 2007 level, holding everything else constant. The results confirm our conjecture that the observed changes in value added shares contributed to trade growth and greater production fragmentation. We repeat the same exercise including also changes in $\alpha$ and $\gamma$, reflecting (exogenous) adjustments in the sectoral composition of demand for final goods and intermediates. We find that changes in demand composition had a positive effect on China's DVA ratio alike the trade policy changes; see row $(\mathrm{g})$. However, these adjustments came with a decline in exports from China and at the world level. It seems important at this stage to recall the model assumption of unitary substitution elasticities between sectoral composites in intermediate and final goods demand, as well as between labor and intermediate goods in the production function. If one allowed for non-unitary elasticities instead, expenditure shares would respond endogenously, for example, to changes in trade costs. Hence, part of the adjustment in expenditure shares observed in the data might in fact be endogenous responses to China's WTO entry. Quantitatively, changes in technology parameters are equally important for global production fragmentation as the trade cost changes.

The measures of production sharing are also affected by changes in trade surpluses. The effect runs through changes in the sectoral composition of exand imports and, in the case of the DVA ratio, also through a change in the amount of reimported domestic value added relative to exports. Changes in inventory stocks, which are part of the OECD ICIO's accounting system, have very similar effects. For China, the real surplus (including inventory changes) increased by a factor eight between 2000 and 2007. Holding everything else constant, China's growth in the surplus contributed to a decline in the DVA ratio at the world level, and an increase in the DVA ratio across all of China's economic segments (see row h). Since surpluses constitute mere transfers in our framework, the large negative welfare effect is not surprising.

Last, we combine all observed trade policy effects (row d) with the changes in transportation costs (row e), technology (row g), and surpluses (row h) to 
analyze how much of the changes in the data we can explain with observed exogenous variables. Provided that we measure these variables, as well as the sectoral dispersion parameters, without substantial error, our model implies that residual observed changes in the data are then to be attributed to (unobserved) changes in productivity levels, $\lambda$. The results presented in row (h) suggest that productivity changes were indeed the driving force behind the growth of China's (world) exports, of which we are able to explain $36 \%(26 \%)$ with observable exogenous variables. Moreover, we find that the observed changes in tariffs and NTBs, expenditure shares, and surpluses have strongly spurred production fragmentation in China - except for the processing segment - and at the world level. Absent other changes, they would have led to much greater declines in domestic value added content ratios than what we actually observed, leaving only a mitigating role for productivitygrowth-driven changes in the sectoral composition of output and trade.

\section{Discussion and Conlusions}

A few comments are in order in regard to the effects of our counterfactual experiments. First, our analysis rests on the assumption that labor is perfectly mobile across sectors within a country. Since sectors are affected very differently, owing both to heterogeneous tariff cuts and different sourcing structures, the assumption of labor mobility clearly matters for whether countries can actually realize the real wage gains predicted by the model, and over what time horizon. Second, in our static framework trade deficits appear as one-time net income transfers that are treated as exogenous and held constant when moving to the counterfactual equilibrium.

Third, our IO-based DVA ratios tend to understate the domestic value added content, since IO tables are typically based on samples where large firms with higher intermediate input shares are overrepresented (see Kee and Tang, 2016). However, disaggregation of China into four production segments with individual IO tables is likely to reduce this bias. Moreover, our analysis focuses on changes, which should be much less or not affected by this issue. Fourth, as mentioned before, the consequences of China's WTO accession were much broader than those we discuss here. Our welfare effects reflect only the changes induced by the tariff cuts and estimated average NTB reductions directly. We do not take into account indirect effects, such as changes in productivity induced by the reallocation of resources among firms or changes in the degree of competition. As shown by Brandt et al. 
(2017), the tariff cuts associated with China's WTO entry brought about significant productivity gains and reduced markups.

Lastly, foreign direct investment (FDI) also underwent substantial liberalization in China in the 2000s (see, e.g., Mattoo, 2003). How FDI may have affected trade with China and the degree of global production sharing is a-priori unclear. Kee and Tang (2016) show that investment liberalization enhanced variety and competitiveness of domestically-produced inputs, which spurred the increase in the processing firms' DVA ratio. ${ }^{13}$ For our counterfactual analysis of tariff cuts this means that we are missing out on an improvement in competitiveness of domestic suppliers and hence overstate (understate) the WTO entry's impact on imports (China's DVA ratio) compared to what we observe in the data. However, labor-cost-saving vertical FDI, for example in the export-processing zones, will have the opposite effect on trade. Offshoring of intermediate production stages to China will increase both China's imports and exports. Entry of foreign firms in the processing or ordinary export segment is likely to have a negative compositional effect on the country-level DVA ratio, since those firms tend to have lower DVA ratios than firms in the other segments.

Given the structure of our model, we cannot include FDI liberalization explicitly into our analysis to come up with a definite answer on the direction of its effect on trade and production fragmentation. However, to the extent that there is a systematic positive or negative effect of WTO-induced FDI liberalization on trade, for example, through TRIMS, it will be picked up by our estimated NTB effects. Moreover, Greaney and Li (2009) show that FDI inflows relative to GDP stayed almost constant between 2000 and 2006, FDI stocks relative to GDP actually decreased. In contrast, trade over GDP surged during that time. These figures suggest that FDI growth was not a dominant effect of China's WTO entry.

Our simulated trade effects for China align well with findings of the empirical literature studying trade effects of WTO membership in the gravity framework. ${ }^{14}$ As regards the magnitude of our predicted welfare effect for China of $1.4 \%$ due to the tariff cuts associated with the WTO entry, we find it to be comparable to the extant literature on trade with China that

\footnotetext{
${ }^{13}$ One important feature of Chinese investment liberalization in the 2000s was that the requirement for foreign firms to export the majority of their output was lifted.

${ }^{14}$ For example, Helpman et al. (2008), Felbermayr and Kohler (2010), and Dutt et al. (2013) find trade effects in the range of 15 to $50 \%$.
} 
uses similar methodology. Ghosh and Rao (2010) find real GDP gains from China's WTO entry of around 2\% in a CGE model. di Giovanni et al. (2014) use a model similar to ours to quantify the overall gains from trading with China. Starting from a baseline equilibrium depicting the world in the 2000s, they find that changing China's status to autarky would entail a welfare loss of $3.7 \%$ for China. Our counterfactual welfare gain for China thus accounts for about 40 percent of China's gains from trade with the world. Compared to an estimated real income gain of around $10 \%$ due to China's productivity growth between 1995 and 2007 (Hsieh and Ossa, 2016), our predicted welfare gains from China's WTO entry also seem plausible.

In conclusion, we analyze the effects of trade liberalization on global production fragmentation and the formation of production networks. To that end, we derive structural expressions for value added trade flows and indicators of production fragmentation, as well as new measures of sectoral production networks, from a multi-sector multi-country general equilibrium trade model. This permits to analyze how production fragmentation is affected by trade policies by means of a counterfactual analysis. We apply our methodology to the case of China's entry into the WTO, which constituted a major shock to global trade in 2001.

Our methodology may also serve as a tool for research on the impact of domestic and trade policies in the presence of global upstream and downstream linkages, such as the exit from or renegotiation of economic integration agreements, or the implementation of domestic taxes with border adjustments. While beyond the scope of our work, a promising avenue for future research is to include FDI into this framework, along the lines of the pioneering work by Anderson et al. (2017). This would render feasible a joint evaluation of trade and investment policies - that often go hand in hand and can complement or substitute for each other.

\section{References}

Anderson, J. E., Larch, M., Yotov, Y. V., 2017. Trade and Investment in the Global Economy. NBER Working Paper 23757.

Antrás, P., Chor, D., 2013. Organizing the Global Value Chain. Econometrica 81 (6), 2127-2204.

Autor, D. H., Dorn, D., Hanson, G. H., 2013. The China Syndrome: Local 
Labor Market Effects of Import Competition in the United States. American Economic Review 103 (6), 2121-68.

Baier, S. L., Bergstrand, J. H., 2007. Do Free Trade Agreements Actually Increase Members' International Trade? Journal of International Economics 71 (1), 72-95.

Baier, S. L., Bergstrand, J. H., Feng, M., 2014. Economic Integration Agreements and the Margins of International Trade. Journal of International Economics 93 (2), 339 - 350 .

Baldwin, R., Lopez-Gonzalez, J., 2015. Supply-chain Trade: A Portrait of Global Patterns and Several Testable Hypotheses. The World Economy 38 (11), 1682-1721.

Baldwin, R., Venables, A. J., 2013. Spiders and Snakes: Offshoring and Agglomeration in the Global Economy. Journal of International Economics 90 (2), 245-254.

Brandt, L., Morrow, P. M., 2017. Tariffs and the Organization of Trade in China. Journal of International Economics 104, 85 - 103.

Brandt, L., Van Biesebroeck, J., Wang, L., Zhang, Y., 2017. WTO Accession and Performance of Chinese Manufacturing Firms. American Economic Review 107 (9), 2784-2820.

Broda, C., Weinstein, D., 2006. Globalization and the Gains from Variety. Quarterly Journal of Economics 121 (2), 541-585.

Caliendo, L., Parro, F., 2015. Estimates of the Trade and Welfare Effects of NAFTA. Review of Economic Studies 82 (1), 1-44.

Costinot, A., Rodríguez-Clare, A., 2014. Trade Theory with Numbers: Quantifying the Consequences of Globalization. In: Gopinath, G., Helpman, E., Rogoff, K. (Eds.), Handbook of International Economics. Vol. 4. Elsevier, Ch. 4, pp. 197-261.

Daudin, G., Rifflart, C., Schweisguth, D., 2011. Who Produces for Whom in the World Economy? Canadian Journal of Economics 44 (4), 1403-1437. 
di Giovanni, J., Levchenko, A. A., Zhang, J., 2014. The Global Welfare Impact of China: Trade Integration and Technological Change. American Economic Journal: Macroeconomics 6 (3), 153-83.

Dutt, P., Mihov, I., Zandt, T. V., 2013. The Effect of WTO on the Extensive and the Intensive Margins of Trade. Journal of International Economics $91(2), 204-219$.

Egger, P., Larch, M., Staub, K. E., 2012. Trade Preferences and Bilateral Trade in Goods and Services: A Structural Approach. CEPR Discussion Papers 9051.

Feenstra, R. C., 1994. New Product Varieties and the Measurement of International Prices. The American Economic Review 84 (1), pp. 157-177.

Felbermayr, G., Kohler, W., 2010. Modelling the Extensive Margin of World Trade: New Evidence on GATT and WTO Membership. The World Economy 33 (11), 1430-1469.

Ghosh, M., Rao, S., 2010. Chinese Accession to the WTO: Economic Implications for China, Other Asian and North American Economies. Journal of Policy Modeling 32 (3), 389-398.

Greaney, T. M., Li, Y., 2009. Assessing Foreign Direct Investment Relationships between China, Japan, and the United States. Journal of Asian Economics 20 (6), $611-625$.

Handley, K., Limão, N., 2017. Policy Uncertainty, Trade, and Welfare: Theory and Evidence for China and the United States. American Economic Review 107 (9), 2731-83.

Head, K., Mayer, T., 2014. Gravity Equations: Workhorse, Toolkit, and Cookbook. In: Gopinath, G., Helpman, E., Rogoff, K. (Eds.), Handbook of International Economics. Vol. 4. Elsevier, Ch. 3, pp. 131-195.

Helpman, E., Melitz, M., Rubinstein, Y., 2008. Estimating Trade Flows: Trading Partners and Trading Volumes. Quarterly Journal of Economics 123 (2), 441-487.

Hsieh, C.-T., Ossa, R., 2016. A Global View of Productivity Growth in China. Journal of International Economics 102 (Supplement C), 209 - 224. 
Hummels, D., Ishii, J., Yi, K.-M., 2001. The Nature and Growth of Vertical Specialization in World Trade. Journal of International Economics 54 (1), 75-96.

Johnson, R. C., Noguera, G., 2012. Accounting for Intermediates: Production Sharing and Trade in Value Added. Journal of International Economics 86 (2), 224-236.

Johnson, R. C., Noguera, G., 2017. A Portrait of Trade in Value-Added over Four Decades. The Review of Economics and Statistics 99 (5), 896-911.

Kee, H. L., Tang, H., 2016. Domestic Value Added in Exports: Theory and Firm Evidence from China. American Economic Review 106 (6), 1402-36.

Keller, W., Yeaple, S. R., 2013. The Gravity of Knowledge. American Economic Review 103 (4), 1414-44.

Koopman, R., Wang, Z., Wei, S.-J., 2012. Estimating Domestic Content in Exports when Processing Trade is Pervasive. Journal of Development Economics 99 (1), 178 - 189.

Koopman, R., Wang, Z., Wei, S.-J., 2014. Tracing Value-added and Double Counting in Gross Exports. American Economic Review 104 (2), 459-494.

Larch, M., Wanner, J., Yotov, Y., Zylkin, T., 2017. The Currency Union Effect: A PPML Re-assessment with High-Dimensional Fixed Effects. Drexel University School of Economics Working Paper Series 2017-7.

Mattoo, A., 2003. China's Accession to the WTO: The Services Dimension. Journal of International Economic Law 6 (2), 299-339.

Mayer, T., Vicard, V., Zignago, S., 2018. The Cost of Non-Europe, Revisited. CEPR Discussion Paper DP12844.

Pierce, J. R., Schott, P. K., 2016. The Surprisingly Swift Decline of US Manufacturing Employment. American Economic Review 106 (7), 163262 .

WTO, 2001. Report of the Working Party on the Accession of China. World Trade Organization. 
Xing, Y., Detert, N., 2011. How the iPhone Widens the United States Trade Deficit with the People's Republic of China. Aussenwirtschaft 66 (03), 339-350.

Yi, K.-M., 2003. Can Vertical Specialization Explain the Growth of World Trade? Journal of Political Economy 111 (1), 52-102.

Yotov, Y. V., Piermartini, R., Monteiro, J.-A., Larch, M., 2016. An Advanced Guide to Trade Policy Analysis: The Structural Gravity Model. WTO and UNCTAD.

\section{Appendix A. Additional Tables}

Table A.1: China's Economy in the Early 2000s

\begin{tabular}{lcccc}
\hline & \multicolumn{3}{c}{2000} & 2007 \\
Shares by segment (in \%) & $Y$ & $V A$ & Exp & Exp \\
\hline Domestic & 45 & 40 & $1^{a)}$ & $0^{a)}$ \\
Ordinary exports & 10 & 9 & 31 & 36 \\
Processing exports & 4 & 2 & 41 & 41 \\
Services & 41 & 49 & 27 & 23 \\
\hline
\end{tabular}

Note: The table shows shares of China's four segments in total output and value added in columns $(1,2)$, and in exports in 2000 and 2007 in columns $(3,4)$. Source: OECD ICIO Database.

a) Sales to non-residents within China's domestic territory. 
Table A.2: Inward and Outward Tariffs with China in 2000 and Changes to 2007, by Country

\begin{tabular}{|c|c|c|c|c|c|c|c|c|c|}
\hline & Inv & vard & Outwa & & & Iny & $\operatorname{ard}$ & Out & ward \\
\hline Country & $\begin{array}{c}\text { Tariff } \\
\%\end{array}$ & $\begin{array}{l}\text { Cut } \\
\% \text { pts }\end{array}$ & $\begin{array}{c}\text { Tariff } \\
\%\end{array}$ & $\begin{array}{l}\text { Cut } \\
\% \mathrm{pts}\end{array}$ & Country & $\begin{array}{c}\text { Tariff } \\
\%\end{array}$ & $\begin{array}{l}\text { Cut } \\
\% \text { pts }\end{array}$ & $\begin{array}{c}\text { Tariff } \\
\%\end{array}$ & $\begin{array}{l}\text { Cut } \\
\% \text { pts }\end{array}$ \\
\hline $\mathrm{ARG}$ & 55.1 & -51.5 & 13.1 & -2.2 & IDN & 4.8 & -2.5 & 5.4 & -1.0 \\
\hline BRA & 25.1 & -22.4 & 10.8 & -2.9 & AUT & 5.0 & -2.5 & 2.2 & -0.0 \\
\hline HUN & 17.9 & -10.7 & 8.3 & -6.3 & DNK & 4.8 & -2.4 & 1.7 & -0.0 \\
\hline $\mathrm{CZE}$ & 11.8 & -6.2 & 2.9 & -0.5 & BEL & 5.4 & -2.1 & 2.4 & -0.1 \\
\hline CAN & 10.0 & -5.7 & 3.8 & -0.3 & SVN & 5.3 & -1.9 & 9.8 & -5.8 \\
\hline USA & 8.3 & -5.7 & 3.1 & -0.5 & SVK & 3.7 & -1.9 & 2.8 & -0.7 \\
\hline KHM & 7.7 & -5.1 & 10.4 & -2.8 & LUX & 3.4 & -1.8 & 2.1 & -0.0 \\
\hline THA & 9.9 & -5.0 & 8.9 & -4.7 & RUS & 4.3 & -1.6 & 5.7 & -1.2 \\
\hline PRT & 8.3 & -4.6 & 2.2 & -0.0 & CRI & 3.2 & -1.5 & 5.1 & -0.3 \\
\hline SWE & 7.1 & -4.5 & 2.9 & -0.0 & HKG & 3.0 & -1.4 & -0.0 & 0.0 \\
\hline DEU & 8.2 & -4.4 & 2.4 & -0.1 & GRC & 4.9 & -1.4 & 2.2 & -0.0 \\
\hline AUS & 8.2 & -4.3 & 5.1 & -1.5 & TUN & 3.3 & -1.3 & 22.6 & -2.8 \\
\hline MYS & 6.5 & -4.2 & 4.5 & -1.6 & IND & 4.5 & -1.2 & 13.8 & -7.3 \\
\hline IRL & 6.5 & -4.1 & 1.4 & -0.0 & $\mathrm{COL}$ & 8.8 & -1.1 & 9.2 & -0.0 \\
\hline POL & 8.3 & -4.0 & 7.4 & -3.6 & ROW & 2.9 & -1.0 & 10.7 & -3.3 \\
\hline FRA & 6.9 & -3.9 & 2.3 & -0.0 & TUR & 2.8 & -0.9 & 5.0 & -0.9 \\
\hline FIN & 6.4 & -3.9 & 2.6 & -0.0 & SAU & 2.1 & -0.9 & 5.1 & -3.0 \\
\hline ESP & 8.1 & -3.9 & 2.3 & -0.0 & NZL & 6.3 & -0.9 & 3.9 & -0.2 \\
\hline TWN & 6.4 & -3.7 & 2.2 & -0.8 & MAR & 7.5 & -0.9 & 21.1 & -4.2 \\
\hline $\mathrm{JPN}$ & 6.5 & -3.6 & 3.4 & -0.6 & NOR & 3.9 & -0.8 & 5.5 & -2.6 \\
\hline VNM & 6.9 & -3.6 & 22.5 & -2.0 & HRV & 3.0 & -0.8 & 10.5 & -6.0 \\
\hline GBR & 5.9 & -3.3 & 2.1 & -0.0 & $\mathrm{ZAF}$ & 3.7 & -0.7 & 8.8 & -0.9 \\
\hline ITA & 6.7 & -3.2 & 2.2 & -0.0 & BGR & 1.9 & -0.6 & 7.3 & -3.9 \\
\hline SGP & 5.7 & -3.2 & 0.0 & 0.0 & LTU & 15.5 & -0.5 & 2.6 & -0.8 \\
\hline PHL & 5.6 & -3.1 & 6.7 & -1.2 & $\mathrm{EST}$ & 3.8 & -0.4 & 0.0 & -0.0 \\
\hline KOR & 6.3 & -3.1 & 21.1 & -1.2 & PER & 1.8 & -0.3 & 9.8 & -1.6 \\
\hline MLT & 2.9 & -2.8 & 7.7 & -3.6 & ISL & 8.4 & -0.3 & 5.7 & -0.0 \\
\hline MEX & 4.0 & -2.8 & 14.2 & -4.7 & CHL & 1.4 & -0.2 & 7.0 & -2.3 \\
\hline ISR & 4.6 & -2.8 & 6.3 & -2.8 & CYP & 0.3 & -0.2 & 5.4 & -0.7 \\
\hline CHE & 6.2 & -2.7 & 6.9 & -1.5 & LVA & 0.7 & -0.1 & 4.0 & -1.5 \\
\hline $\mathrm{ROU}$ & 11.6 & -2.7 & 11.6 & -7.4 & BRN & 0.0 & -0.0 & 0.7 & -0.1 \\
\hline NLD & 7.0 & -2.6 & 2.5 & -0.1 & & & & & \\
\hline
\end{tabular}

Note: The table shows trade-weighted average tariffs in 2000 and tariff changes between 2000-2007 by country imposed by China on imports (Inward) and faced by Chinese exporters (Outward). Tariff changes reflect the difference between trade-weighted 2000 applied tariffs to MFN levels in 2007. Only tariff changes are included where the applied tariff in 2000 exceeds the MFN level in 2007 at the HS-6-digit level. Trade flows from 2000 are used to aggregate tariffs from the HS-6-digit level to the country level. 
Table A.3: Sectoral Tariff Changes, 2000-2007

\begin{tabular}{clcccc}
\hline ISIC & Sector & $\begin{array}{c}\text { Inward } \\
\%\end{array}$ & $\begin{array}{c}\text { Tariff Cut } \\
\% \text { pts }\end{array}$ & $\begin{array}{c}\text { Outward } \\
\%\end{array}$ & $\begin{array}{c}\text { Tariff Cut } \\
\% \text { pts }\end{array}$ \\
\hline $01-05$ & Agriculture, fishing & 44.7 & -36.9 & 64.3 & -3.7 \\
34 & Motor vehicles & 31.7 & -18.5 & 4.4 & -1.6 \\
15,16 & Food, beverages & 29.4 & -10.0 & 13.5 & -1.8 \\
$36-37$ & Other manufacturing & 17.7 & -7.3 & 2.4 & -0.7 \\
29 & Machinery \& equipment & 10.9 & -5.6 & 3.4 & -1.2 \\
$30,32-33$ & Other equipment & 6.8 & -4.9 & 1.9 & -0.7 \\
$17-19$ & Textiles, leather & 8.9 & -4.8 & 10.4 & -1.5 \\
25 & Rubber \& plastics & 9.1 & -4.1 & 4.9 & -0.9 \\
24 & Chemicals & 7.2 & -3.5 & 4.2 & -1.6 \\
31 & Electronics & 6.2 & -3.2 & 3.7 & -1.3 \\
21,22 & Paper, publishing & 5.1 & -3.0 & 2.7 & -1.2 \\
20 & Wood & 4.3 & -2.9 & 2.6 & -0.4 \\
35 & Other transport equip. & 5.8 & -1.9 & 13.1 & -2.4 \\
26 & Other minerals & 6.2 & -1.6 & 5.6 & -1.0 \\
23 & Coke, petroleum & 7.8 & -1.5 & 4.0 & -1.4 \\
28 & Metal products & 5.1 & -1.4 & 4.5 & -1.1 \\
27 & Basic metals & 3.8 & -1.3 & 3.9 & -1.7 \\
$10-14$ & Mining \& quarrying & 0.1 & -0.0 & 1.4 & -0.7 \\
\hline
\end{tabular}

Note: The table shows trade-weighted average tariffs in 2000 and tariff changes between 2000-2007 by sector imposed by China on imports (Inward) and faced by Chinese exporters (Outward). Tariff changes reflect the difference between trade-weighted 2000 applied tariffs to MFN levels in 2007. Only tariff changes are included where the applied tariff in 2000 exceeds the MFN level in 2007 at the HS-6-digit level. Trade flows from 2000 are used to aggregate tariffs from the HS-6-digit level to the sector level (ISIC Rev. 3). 
Table A.4: Sectoral Trade Elasticities and Changes in Tariff-Equivalents of NTBs

\begin{tabular}{|c|c|c|c|c|c|}
\hline ISIC & Sector & $\theta$ & $\begin{array}{c}\text { WTO } \\
\%\end{array}$ & $\begin{array}{c}\text { PTA } \\
\%\end{array}$ & $\begin{array}{c}\mathrm{CCU} \\
\%\end{array}$ \\
\hline 01-05 & Agriculture, fishing & 8.1 & -7.8 & -2.2 & -3.7 \\
\hline $10-14$ & Mining \& quarrying & 15.7 & -2.4 & 0.7 & -2.4 \\
\hline 15,16 & Food, beverages & 2.5 & -4.6 & -5.2 & -10.2 \\
\hline $17-19$ & Textiles, leather & 5.6 & -0.6 & 2.9 & 2.2 \\
\hline 20 & Wood & 10.8 & -0.7 & 1.2 & 0.5 \\
\hline 21,22 & Paper, publishing & 9.1 & -2.0 & 1.4 & -1.4 \\
\hline 23 & Coke, petroleum & 51.1 & -5.9 & 11.8 & 6.1 \\
\hline 24 & Chemicals & 4.8 & -3.8 & -1.9 & -7.0 \\
\hline 25 & Rubber \& plastics & 1.7 & -27.6 & -13.4 & -27.9 \\
\hline 26 & Other minerals & 2.8 & 3.9 & -0.9 & -3.5 \\
\hline 27 & Basic metals & 8.0 & -5.8 & -2.5 & -5.6 \\
\hline 28 & Metal products & 8.0 & -0.4 & 0.7 & -1.4 \\
\hline 29 & Machinery \& equipment & 1.5 & -1.7 & -19.4 & -25.7 \\
\hline $30,32,33$ & Other equipment & 10.6 & 0.5 & 2.9 & 0.9 \\
\hline 31 & Electronics & 10.6 & -2.6 & 1.9 & -0.1 \\
\hline 34 & Motor vehicles & 0.4 & -28.9 & -57.7 & -81.4 \\
\hline 35 & Other transport equip. & 0.4 & -24.5 & -8.0 & 70.4 \\
\hline $36-37$ & Other manufacturing & 5.0 & 6.2 & -3.9 & -4.9 \\
\hline 40,41 & Electricity, gas, water & 5.0 & -2.0 & -5.8 & -19.4 \\
\hline 45 & Construction & 5.0 & -2.4 & -9.7 & -4.2 \\
\hline $50-52$ & Wholesale, retail trade & 5.0 & -1.2 & -1.9 & -5.5 \\
\hline 55 & Hotels \& restaurants & 5.0 & -0.1 & -1.3 & -4.6 \\
\hline $60-63$ & Transport \& storage & 5.0 & -0.1 & -0.6 & -0.6 \\
\hline 64 & Post, telecommunication & 5.0 & -0.4 & -4.1 & -10.3 \\
\hline $65-67$ & Financial services & 5.0 & -0.5 & -1.0 & 3.8 \\
\hline 70 & Real estate services & 5.0 & 1.9 & -1.8 & -6.5 \\
\hline 71 & Renting of machinery & 5.0 & 1.1 & -3.3 & -13.4 \\
\hline 72 & Computer services & 5.0 & 4.5 & -3.2 & -13.1 \\
\hline $73-74$ & R\&D and business serv. & 5.0 & -2.0 & -4.5 & -4.6 \\
\hline 75 & Social services & 5.0 & 4.8 & -7.4 & -5.4 \\
\hline 80 & Education & 5.0 & 6.7 & -4.2 & -9.8 \\
\hline 85 & Health \& social work & 5.0 & 3.3 & -0.8 & -8.5 \\
\hline $90-95$ & Other services & 5.0 & 1.5 & -6.3 & -14.1 \\
\hline
\end{tabular}

Note: Column (3) shows the trade elasticities $(\theta)$ used in our main specification, which are taken from Caliendo and Parro (2015) (for goods sectors ISIC 01-37) and Egger et al. (2012) (for services ISIC 40-95). Goods trade elasticities are applied to our slightly more aggregated sector classification in a way similar to Costinot and Rodríguez-Clare (2014). Column (4) $(5,6)$ shows estimated changes in tariff equivalents of joint membership in the WTO (a PTA, a CCU) based on an estimation described in Section 5.3.1. Bold faced estimates are significant at the $10 \%$ significance level or hider. 